\title{
Reconceptualizing Cognitive Media Effects Theory and Research Under the Judged Usability Model
}

\author{
ByungGu Lee \\ Independent Researcher \\ nanhyang9@gmail.com
}

\author{
Douglas M. McLeod \\ University of Wisconsin-Madison \\ dmmcleod@wisc.edu
}

\begin{abstract}
This review synthesizes the existing literature on cognitive media effects, including agenda setting, framing, and priming, in order to identify their similarities, differences, and inherent commonalities. Based on this review, we argue that the theory and research on each of these cognitive effects share a common view that media affect audience members by influencing the relative importance of considerations used to make subsequent judgments (including their answers to post-exposure survey questions). In reviewing this literature, we note that one important factor is often ignored, the extent to which a consideration featured in the message is deemed usable for a given subsequent judgment, a factor called judged usability, which may be an important mediator of cognitive media effects like agenda setting, framing, and priming. Emphasizing judged usability leads to the revelation that media coverage may not just elevate a particular consideration, but may also actively suppress a consideration, rendering it less usable for subsequent judgments. Thus, it opens a new avenue for cognitive effects research. In the interest of integrating these strands of cognitive effects research, we propose the Judged Usability Model as a revision of past cognitive models.
\end{abstract}

Suggested citation: Lee, B., Mcleod, D. (2020). Reconceptualizing Cognitive Media Effects Theory and Research Under the Judged Usability Model. Review of Communication Research, 8, 17-50. doi:10.12840/ISSN.2255-4165.022

Keywords: Media Effects, Cognitive Media Effects, Framing Effects, Agenda-setting, Priming, News Framing, Judged Usability Model

Editor: Giorgio P. De Marchis (Universidad Complutense de Madrid, Spain).

Reviewers: Marcus Maurer (Johannes Gutenberg University Mainz, Germany), two reviewers prefer to stay anonymous

Received: Sept. $5^{\text {th }}, 2019$ Open peer review: Sept. $6^{\text {th }}$ Accepted: Jan. 19 Ath $^{\text {th }} 2020$ Published: Jan. 2020 


\section{Highlights}

- This review evaluates existing theory and research pertaining to the cognitive media effects of agenda setting, priming, and framing.

- Accessibility-based explanations typically used to account for agenda-setting and priming effects are shown to be inadequate.

- Judged usability, an evaluation of whether a consideration is useful in making subsequent judgments, is suggested as a common mediator shaping cognitive media effects.

- Theory and research are synthesized into a Judged Usability Model, representing the common psychological processes of agenda setting, framing, and priming.

- At the heart of the Judged Usability Model is the equation: Judgment $=\sum U_{i}{ }^{*} E_{i}$, where $U_{i}$ is the judged usability of consideration $i$, and $E_{i}$ is the evaluation of the target on consideration $i$.

- Judged usability is further broken down into the equation: $\mathrm{JU}=\sum I_{i}{ }^{*} R_{i}$, where $I_{i}$ is the perceived importance of consideration $i$, and $R_{i}$ is the perceived relevance of consideration $i$.

- The influence of judged usability standards is moderated by the judged certainty of each of these judgments.

- The Judged Usability Model raises the prospect of reverse agenda setting and reverse priming, the potential for a message to reduce the importance of a judgment consideration.

\section{Content}

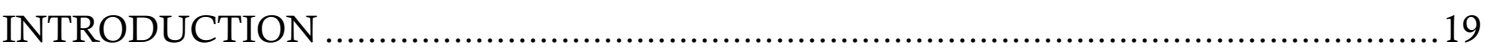

OVERVIEW OF AGENDA SETTING, PRIMING, AND FRAMING ........................19

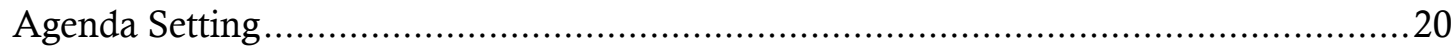

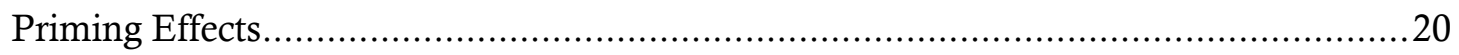

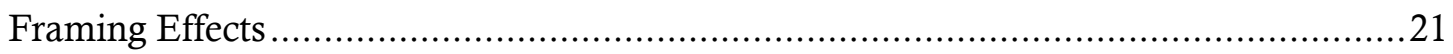

COGNITIVE PSYCHOLOGICAL APPROACHES TO AGENDA SETTING,

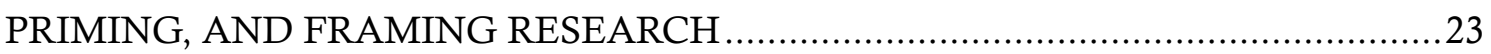

PSYCHOLOGICAL MECHANISMS OF AGENDA SETTING, PRIMING, AND

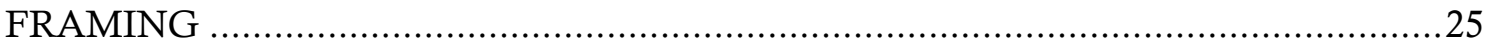

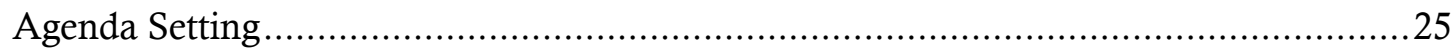

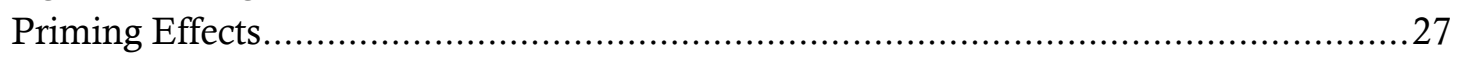

Empirical Evidence Draws the Accessibility Bias Hypothesis into Question ................27

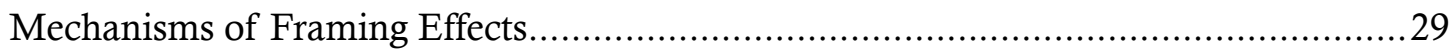

REDEFINING THE RELATIONSHIPS AMONG AGENDA SETTING,

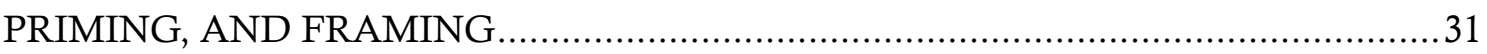

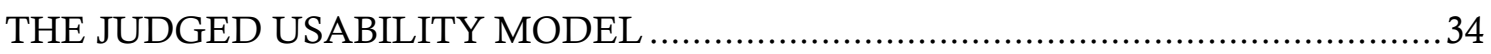

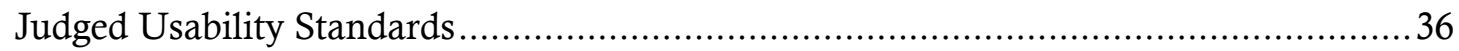

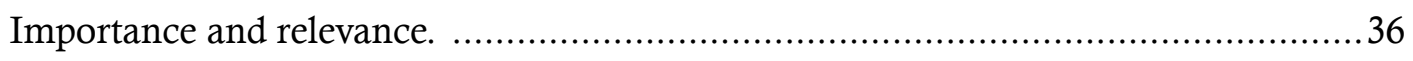

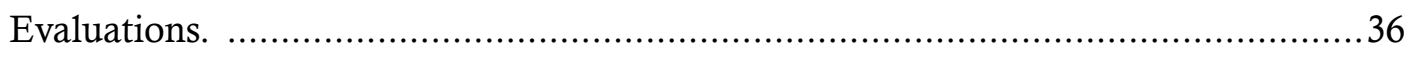

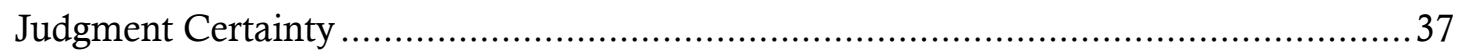

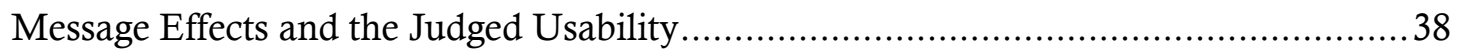

REVERSE AGENDA SETTING AND REVERSE PRIMING .................................... 38

Other Reverse Agenda Setting and Reverse Priming Mechanisms. ............................4 41

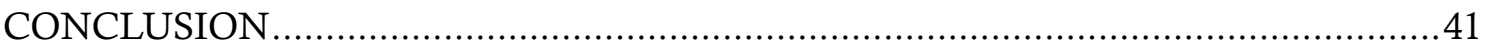

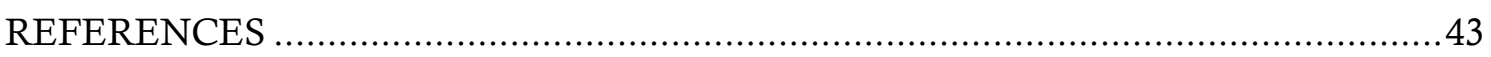

COPYRIGHTS AND REPOSITORIES …........................................................... 50 


\section{Introduction}

Our review of theory and research on cognitive media effects begins by examining the existing literature on the cognitive effects of mass communication, which prominently features three related effects: agenda setting, framing, and priming. Each of these areas has generated a voluminous stream of research. Moreover, researchers have made numerous attempts to articulate their similarities and differences, as well as the nature of their interrelationships. While some scholars have argued that these media effects perspectives have commonalities, but are conceptually distinct (Kosicki, 1993; Maher, 2001; Scheufele, 2000), others have asserted that one of these effects, agenda setting in particular, may subsume the others (Iyengar \& Simon, 1993; McCombs \& Ghanem, 2001; McCombs, Shaw, \& Weaver, 1997).

Our review of the cognitive effects literature suggests that there are common psychological processes shared by agenda-setting, framing, and priming effects. From our perspective, they share a concern for how mass media influence the relative importance and relevance of considerations (such as particular issues and certain aspects of an issue) used to make subsequent judgments. For agenda setting, selective media attention leads people to perceive that issues featured in news stories are important, relevant, or both to the judgment task of naming the most important problem (MIP) facing the nation. Framing effects concern how the narrative structure of a news story influences the importance, relevance, or both of certain considerations in judging actors or issues featured in the story. Media priming effects involve rendering certain considerations (usually issues) featured in a message more important, relevant, or both to the evaluation of politicians. Thus, each of these cognitive effects models involves media messages that elevate featured cognitive considerations used in making subsequent judgments.

There have been several attempts to articulate an underlying model to represent the cognitive concepts and processes at the heart of these cognitive effects. In reviewing the literature, we found that insufficient attention has been paid to the impact of media messages on the extent to which the featured consideration is deemed usable for a given judgment, namely, judged usability (Higgins, 1996; Price \& Tewksbury, 1997). In fact, findings suggest that those cognitive effects models are a product of substantiating the usability of a consideration for a given judgment (Althaus \& Kim, 2006; Geer, 1991; Miller, 2007; Miller \& Krosnick, 2000; Nelson, Oxley, \& Clawson, 1997). Thus, judged usability is an important mediator that shapes cognitive media effects like agenda-setting, framing, and priming effects. As such, cognitive effects models should take usability judgments into account.

To that end, we propose a revised model of cognitive effects, which we label the Judged Usability Model. This model builds on past models by considering not only audience members' evaluations of a particular consideration (e.g., agreeing or disagreeing that carrying a concealed gun protects the bearer), but also their assessments of the usability of that consideration for a given judgment (e.g., importance and relevance of the self-protection consideration to the enactment of concealed carry laws). It recognizes consideration evaluation and usability as distinct cognitive assessments.

Moreover, our inclusion of judged usability leads us to the revelation that messages may not just elevate a particular consideration, but message content may actively suppress a consideration, rendering it less usable for subsequent judgments. As a logical derivative of our judged usability model, therefore, we introduce the reverse agenda setting and reverse priming hypotheses-the ability of media messages to suppress certain considerations from serving as a judgment standard-as a particular type of media effect that is theoretically integrated with its priming counterpart in a larger theoretical model of cognitive media effects.

Our review begins with an assessment of the cognitive effects literature and the existing models that have been used to represent the underlying processes involved in these cognitive effects. This literature review leads us to reconsider the relationships between these cognitive effects, which then inspired us to develop our revised cognitive effects model, the Judged Usability Model. With this new model as our point of departure, we discuss the potential for reverse agenda setting and reverse priming, which may open a new avenue for cognitive effects research.

\section{Overview of Agenda Setting, Priming, and Framing}

We begin our articulation of a new comprehensive model of cognitive media effects by examining the major existing 
strands of research in the cognitive effects domain, namely, agenda setting, framing, and priming. In doing so, we recognize that a considerable amount of scholarly attention has been devoted to explicating their theoretical similarities and dissimilarities, as well as the nature of their relationship to each other.

\section{Agenda Setting}

Grounded in Cohen's (1963) often-cited insight that the press "may not be successful much of the time in telling people what to think, but it is stunningly successful in telling its readers what to think about" (p. 13), McCombs and Shaw's (1972) seminal research on agenda setting shows that mass media have the ability to influence public agendas in accordance with media agendas. Specifically, the researchers found a strong correlation between the rank-order of local and national news media agendas, on the one hand, and the rank-order of issues that participants named as nationally important, on the other.

The early work on agenda setting focused largely on replicating the original findings and identifying contingent conditions (McCombs \& Shaw, 1993). Scholars generally affirmed the robustness of news media's agenda-setting ability (e.g., Benton \& Frazier, 1976; Cook et al., 1983; Shaw \& McCombs, 1977; Weaver, Graber, McCombs, \& Eyal, 1981). For example, Benton and Frazier (1976) found that newspapers were not only capable of shaping public agenda, but also effective at increasing awareness and knowledge of proposed solutions to public issues. Moreover, scholars (e.g., Cook et al., 1983; Shaw \& McCombs, 1977; Weaver et al., 1981) found that not only ordinary citizens' agendas, but also political elites' agendas correspond to issues to which news media pay attention. Regarding the concern that public agendas may be driven by real-world cues rather than by media coverage of issues, Iyengar and Kinder (1987) demonstrated in a series of experiments that news coverage alone is sufficient to shape citizens' perceptions of issue priorities.

Subsequently, scholars turned their attention to variables that influence agenda-setting effects. Most notably, the need for orientation (NFO), "the tendency of an individual to seek information about an issue in the news media" (Matthes, 2006, p. 2), has been found to influence the extent to which agenda-setting effects emerge - those who experience a high need for cognition are more susceptible to agenda setting than those who do not (McCombs \& Weaver, 1973; Weaver,
1977, 1980). Later scholars have concluded that NFO is a predictor of agenda-setting effects (e.g., N. Y. Lee, 2016; Matthes, 2008). Likewise, political involvement (Rogers, Hart, \& Dearing, 1997), the type of information source (Carpentier, 2014), and the amount of direct experience with the issue in question (McCombs \& Estrada, 1997) were found to influence agenda-setting effects.

The emergence of new forms of news media such as online news, cable TV news channels, and blogs has helped agenda-setting research continue to grow. Researchers (e.g., Althaus \& Tewksbury, 2002; Waal \& Schönbach, 2008) found that the online newspapers were able to direct public attention to certain issues just like print newspapers, though readers of print newspapers exhibited interest in a broader range of political and public affairs issues. Meraz (2009) demonstrated that non-traditional online news sources such as political news blogs also have the ability to shape the public agenda. Conway, Kenski, and Wang (2015) found that intermedia agenda-setting effects were present among the Twitter feeds of the 2012 presidential candidates, Twitter feeds of the Democratic and Republican parties, and news stories from traditional media.

\section{Priming Effects}

Priming effects stipulate that issues receiving increasing media attention play a more important role than before in evaluating political figures. The priming hypothesis was first proposed by Iyengar, Peters, and Kinder (1982) based on the speculation that agendas set by the media may alter the standards citizens use in evaluating the president; that is, for example, if national defense is considered an important issue, then how that issue is handled becomes increasingly important in evaluating the performance of the president. Their experiments demonstrated that news coverage of various issues including national defense, pollution, and inflation strengthened the correlation between evaluations of respective policy issues and judgments of President Carter's job performance.

Subsequently, scholars labored to test the hypothesis across topics and methodologies. Adding generalizability, a wide variety of topics have been found to be responsive to media attention including, but not limited to, foreign policy (Krosnick \& Kinder, 1990; Stoycheff \& Nisbet, 2017), war (Althaus \& Kim, 2006; Iyengar \& Simon, 1993), energy policy, national defense, inflation (Iyengar, Kinder, Peters, 
\& Krosnick, 1984), crime (Valentino, 1999), racial attitudes (Luttig \& Callaghan, 2016; Skinner \& Cheadle, 2016) and economic recession (Pan \& Kosicki, 1997). These studies have demonstrated that the media are capable of promoting issues as a political evaluation standard. It is interesting to note, however, that issues that are already highly salient may not be responsive to increasing media attention. Iyengar et al. (1984) found that the economy, which was a very prominent issue at the time of the experiment, did not play a more important role when participants were exposed to economic news. The researchers conjectured that since citizens were already well aware of the significance of the issue, additional information did not increase the weights accorded to the issue.

Studies using various methodologies support the priming hypothesis. Iyengar and colleagues (e.g., Iyengar \& Kinder, 1987; Iyengar et al., 1984) conducted a series of experiments to demonstrate that it is exposure to news stories that causes the alteration of political evaluation standards. Field studies also found support for the priming hypothesis. By utilizing rolling cross-section surveys, Krosnick and Kinder (1990) documented that after the revelation of the Iran-Contra scandal, the influence of foreign policy on President Reagan's job performance evaluations significantly increased (see also Iyengar \& Simon, 1993; Johnston, Andre Blais, Henry E. Brady, \& Jean Crete, 1992; Mendelberg, 2001; Mutz, 1998). In an attempt to more directly observe priming effects in the context of voting decisions, Druckman (2004) combined a content analysis of campaign news stories and an exit poll on Election Day, taking advantage of the 2000 campaign for the U.S. Senate in Minnesota. This study revealed that voters who were attentive to campaign coverage were more likely to base their votes on the issues emphasized in the campaign, whereas those who were oblivious did not rely on those issues when casting their votes. Additionally, Althaus and Kim (2006) utilized news coverage about the 1990-91 Persian Gulf Crisis from major television networks and public opinion data in order to track daily changes in priming effects. The researchers found that both recent and cumulative news exposure were responsible for changes in the impact of issue-specific attitudes on President Bush's job approval ratings.

Along with the basic media priming hypothesis, researchers have documented related phenomena such as the gradient hypothesis and the hydraulic pattern of media priming. Based on the associative network model (J. R. Anderson,
1983), which suggests that activation of a target consideration will activate related considerations with a lesser degree, the gradient hypothesis proposes that news coverage of a target issue activates not only thoughts about that issue, but also thoughts about issues related to the target issue in decreased strength. For example, Iyengar et al. (1984) found that priming President Carter's energy performance had an impact on evaluations of his overall performance, as well as his competence and integrity to a lesser degree.

On a related note, Domke, Shah, and Wackman (1998) revealed that the scope of mobilizing related considerations depends on the extent to which considerations are strongly interconnected. Specifically, the researchers found that evangelical Christians were more likely to make ethical interpretations of a stimulus material than undergraduate students presumably by bringing up more ethical considerations. Additionally, the hydraulic pattern of media priming suggests that issues neglected by mass media are likely to be "pushed into the cognitive background" (Miller \& Krosnick, 1996, p. 82) because people have only limited capability of carrying issues at the same time (Zhu, 1992). Thus, increased weight attached to an issue by virtue of media focus on that issue takes place at the expense of other issues. In this regard, Krosnick and Kinder's (1990) classic priming study illustrated that the rise of the Iran-Contra scandal as a presidential evaluation standard coincided with a considerable decrease in the impact of aid to blacks.

\section{Framing Effects}

Researchers from a variety of fields including psychology (Kahneman \& Tversky, 1984), economics (Kahneman \& Tversky, 1979), sociology (Goffman, 1974), and communication (Entman, 1991) have contributed to the development of two unrelated traditions of framing research. The first approach, often referred to as equivalency framing (Druckman, 2001b), is rooted in the widely cited Asian disease experiment conducted by Tversky and Kahneman (1981). In their experiment, participants were presented with two alternative programs to combat an unusual disease, which is expected to kill 600 people. The first set of programs describes:

If Program A is adopted, 200 people will be saved.

If Program B is adopted, there is a $1 / 3$ probability that 600 people will be saved, and a $2 / 3$ probability that no people will be saved.

It is important to note that both programs have the same 
logical outcome, while Program A presents a risk-averse choice and Program B does a risk-seeking choice. The results show that $72 \%$ of the participants chose Program A, whereas only $28 \%$ preferred Program B. The researchers presented another group of participants with a different formulation of the alternative programs:

If Program C is adopted, 400 people will die.

If Program $D$ is adopted, there is $1 / 3$ probability that nobody will die, and $2 / 3$ probability that 600 people will die.

Even though these programs are logically equivalent to the first set of programs, the preferences exhibited by participants were reversed-22\% preferred Program C, whereas $78 \%$ preferred Program D. These results illustrate that logically equivalent information can elicit starkly different responses depending on which interpretation is emphasized.

Numerous studies conducted in various contexts have shown the robustness of equivalency framing effects (e.g., Liu, Choung, Lee, \& McLeod, 2018; Nabi, Gustafson, \& Jensen, 2018; Pedersen, 2017; Pedersen \& Larsen, 2019; Zahry \& Besley, 2019). For example, Quattrone and Tversky (1988) demonstrated that a policy framed as reducing the unemployment rate from $10 \%$ to $5 \%$ as opposed to one framed as increasing the employment rate from $90 \%$ to $95 \%$ received more endorsements due to a comparatively larger change ratio. Moreover, Lee, Liu, Chong, and McLeod (2019) revealed that displaying crime rates in different formats (e.g., 296.4 million of 319 million Americans vs. 92.9\% of Americans) produced distinct emotional outcomes, which then shaped risk perceptions.

The other approach, referred to as emphasis framing (Druckman, 2001b), examines the differential effects of news stories that are organized around a different central structuring idea. This framing perspective is rooted in Goffman's (1974) conception that frames are a device that enables audience members "to locate, perceive, identify and label" diverse social events. Observing that journalists actively construct social reality rather than plainly describe events or occurrences, Gitlin (1980) defined frames as

Persistent patterns of cognition, interpretation and presentation of selection, emphasis and exclusion, by which symbol handlers routinely organize discourse, whether verbal or visual. Frames enable journalists process large amounts of information quickly and routinely: to recognize it as information, to assign it to cognitive categories, and to package it for efficient relay to their audiences. (p. 7)

Much of the early research in this tradition focused on how news stories are constructed as a product of interactions between journalists and political elites (e.g., Gitlin, 1980). Subsequent to that, researchers began to examine questions about the impact of these media frames on audiences, known as framing effects research. For example, Iyengar (1991) found that episodic news coverage of poverty, which "depicts public issues in terms of concrete instances," led people to attribute responsibility of poverty to the poor (p. 14). In contrast, those who saw thematic news reports, which put "public issues in some more general abstract context," were more likely to hold society responsible for the issue (Iyengar, 1991, p. 14).

Framing effects have been interpreted within a socialcognitive information processing framework (e.g., Chong \& Druckman, 2007b; Nelson, Oxley, et a1., 1997; Price \& Tewksbury, 1997, p. 199). At the first level, media frames tend to elicit particular trains of thought that are consistent with the frames. For instance, Shen (2004) showed that political ads focusing on the candidate's character were more likely to evoke character-related thoughts than thoughts about their issue positions. Similarly, Price, Tewksbury, and Powers (1997) demonstrated that news stories highlighting different aspects of a plan to reduce higher education funding (e.g., conflict surrounding the plan, human interests, and consequences) led people to list more thoughts that are related to the frame they were exposed to than other relevant thoughts. At the subsequent level, thoughts generated by frames play an important role in shaping judgments that follow. When people on welfare are described as not deserving special treatment, for example, beliefs about individual causes of poverty (e.g., lack of effort or thrift) play a more important role than otherwise in making up one's mind about welfare policy (Nelson, Oxley, et al., 1997).

The two framing approaches discussed above (i.e., equivalency vs. emphasis framing) differ in their nature. According to Druckman (2001b), equivalency framing and emphasis framing make different assumptions about humans as an idealized decision makers. Equivalency framing illustrates that individuals do not always make rational choices by showing that people react differently to logically identical information (e.g., Tversky \& Kahneman, 1981). By contrast, emphasis frames do not assume preference invariance. People may shift, for example, from supporting a hate group's right to rally to opposing it because they come to 
believe that public safety concerns trump free speech. According to Druckman (2001b), therefore, emphasis framing can be attributed to bringing up a substantively different consideration at the expense of alternative considerations, not to describing a single piece of information positively or negatively (or in otherwise equivalent terms).

Another difference comes down to what Shah, McLeod, Gotlieb, and N.-J. Lee (2010) referred to as precision vs. realism. Because equivalency framing preserves logical consistency of the factual information while shifting the message frames, the locus of effects can be more precisely determined (i.e., high internal validity). Scholars who advocate the precision approach (e.g., Liu \& Scheufele, 2016) argue that equivalency framing can help distinguish framing effects from other information-based outcomes, such as the secondlevel agenda-setting, priming or persuasion effects, thereby lending "framing" research more legitimacy.

It is obvious, however, that not all issues or events can be described in a way that the logical outcomes of given perspectives are identical. In fact, journalists "may alter the selection of textual packages, the facts, sources, and targets that correspond with the frame" (Shah et al., 2010, p. 87; see also Entman, 1993). As a result, for example, the controversy over the development of nuclear power is likely to be described in a way that highlights the benefits of increased energy independence or in a way that emphasizes the potential environmental consequences of nuclear leaks (Gamson \& Modigliani, 1989), with each of these frames constituting qualitatively different alternatives. Though sacrificing the ability to precisely identify the locus of effects due to the use of qualitatively different information, emphasis framing excels in its ecological validity and is useful to investigate "the essence of public opinion formation" (Chong, 1993, p. 870 ) because it attempts to reproduce variations in the realworld media discourse.

As a result of these inconsistencies in framing research, Entman (1993) critiqued framing as a "fractured paradigm" (p. 51). He maintained that "nowhere is there a general statement of framing theory that shows exactly how frames become embedded within and make themselves manifest in a text, or how framing influences thinking" (p. 51). In response to Entman (1993), McLeod and Shah (2015) integrated compatible approaches to framing research and proposed the Message Framing Model. Their model extends the traditional concept of message frames (i.e., a series of narrative scripts that organize information into a news story) by identifying lower level textual units that carry a particular meaning that are assembled to create a message frame. Specifically, concept frames refer to the labels that journalists choose to describe certain objects or ideas (e.g., freedom fighters vs. terrorists), which signal different interpretations to the audience (also known as cueing effects). By selectively assembling words into sentences, journalists make statements that further transmit preferred meanings, known as assertion frames (e.g., safety assertions that involve statements about whether current or future conditions are safe or unsafe from the risk). These assertions are then logically organized to form arguments, known as thematic framing, which are then assembled into a news story. Thus, the choices journalists make in constructing news stories can deliver meaning through each of these levels of the news story text.

\section{Cognitive Psychological Approaches to Agenda Setting, Priming, and Framing Research}

Among several psychological structure models, the Associative Network Model (J. R. Anderson, 1983) provides an informative framework that identifies the psychological paths by which cognitive media effects (i.e., agenda setting, framing, and priming) occur (Price \& Tewksbury, 1997). According to this model, a construct (i.e., a psychological unit containing knowledge, goals, values, motivations, and affective states) forms horizontal ties with related ideas (J. R. Anderson, 1983). Thus, when a construct is activated by a stimulus material, thoughts related to that construct are also stimulated to the extent that they form strong ties with the construct (Collins \& Loftus, 1975). For example, a news story covering disputes about laws allowing citizens to carry concealed weapons (CCW) may prompt concerns about threats to public safety for individuals who are predisposed to oppose such laws, while, for pro-gun individuals, it may conjure up images of self-protection using a handgun.

In illustrating the psychological paths by which agenda setting, framing, and priming operate, Price and Tewksbury (1997) suggested that such effects are a product of the interaction of knowledge store, current stimuli, and active thought. Knowledge store is a mental container where available and accessible constructs are located. Here, availability refers to "whether or not some particular knowledge is actually stored in memory" (Higgins, 1996, p. 134), while accessibility concerns the ease with which one can retrieve 
available knowledge for conscious processing in working memory, or "the activation potential of available knowledge" (Higgins, 1996, p. 134).

A construct can have two accessibility states: chronic and temporary. Chronic accessibility refers to a high level of activation potential constantly carried by a construct so that it can be reliably activated across various priming conditions (e.g., reading news stories). For example, news stories covering controversies over concealed carry laws may reliably prompt public safety concerns for gun-control activists, while such stories may consistently conjure up images of successfully protecting oneself using a handgun for gun-rights advocates. Temporary accessibility is a state in which a construct momentarily has a greater likelihood of being activated as a result of being activated recently, frequently, or both (Price \& Tewksbury, 1997). For instance, watching a nature documentary, which activates thoughts about the environment, may prioritize environmental concerns when a new large-scale development plan is discussed.

Current stimuli refer to external stimuli that perceivers are processing (Price \& Tewksbury, 1997). In mass communication research, current stimuli typically involve media messages such as broadcast news stories and newspaper articles, which stimulate constructs in knowledge store in a certain way to produce a particular response. It should be emphasized that not all features of a stimulus material are influential because audience members selectively attend to message features (Price \& Tewksbury, 1997; Higgins, 1996). For example, when reading a news story about the pros and cons of people carrying a concealed handgun, arguments supporting the practice are more likely to register in a gunrights activist's mind than ones discrediting his or her position as a result of selective attention and perception. Moreover, the extent to which the attended features of a stimulus material matches existing constructs in the knowledge store is the other determining factor, besides accessibility, in activating a construct, namely, applicability (Higgins, 1996). In other words, applicability concerns how consistent attended features of a message are with the existing constructs in one's knowledge store and, thus, operates before knowledge activation. As knowledge activation is a function of accessibility and applicability (Higgins, 1989), an increase in construct applicability enhances the likelihood that the construct becomes activated.

Noteworthy in the context of applicability is the concept of salience. Emphasizing the distinct contributions of acces- sibility and salience to knowledge activation, Higgins (1996) conceptualized salience as "something about a stimulus event that occurs on exposure, without a prior set for a particular kind of stimulus, that draws attention selectively to a specific aspect of the event" (p. 135, italics in original). In many instances, researchers do not discriminate between different sources of salience including message characteristics (e.g., sustained discussion of a particular perspective, more air time given to a particular consideration, and use of striking images) and audience characteristics (e.g., goals and motivations). A1though Higgins (1996) stressed that this approach is not entirely invalid, he cautioned that such a practice stands a chance of confounding stimulus attributes (e.g., framing an issue in a particular way) with perceiver characteristics (e.g., already accessible ideas such as political ideology) in discerning differential contributions of such factors to knowledge activation. Thus, it is important to distinguish different sources of salience to precisely determine the locus of activation.

Knowledge activation is a function of accessibility and applicability (Higgins, 1989). Regarding their roles, Higgins and Brendl (1995) found some "activation rules." The first rule prescribes that the failure to attain a sufficient level of applicability due to, for example, exposure to vague stimulus can be compensated by strong accessibility. If the consideration "conceited" is highly accessible, for instance, a description of another person that is tangentially related to both "conceited" and "self-confident" can activate thoughts about "conceited." The second rule postulates that "when the applicability of a competing alternative construct is both strong and stronger than the target construct's applicability," activation of highly accessible consideration is inhibited (Higgins \& Brendl, 1995, p. 240). For example, although the consideration "conceited" is highly accessible, reading a description about a hypothetical person's behaviors that is strongly related to "self-confident" or that is more strongly related to "self-confident" than "conceited" constrains the impact of "conceited" on the judgments of the target person. These findings suggest that accessibility and applicability make an independent contribution to knowledge activation (Higgins \& Brendl, 1995).

Lastly, active thought refers to the domain of working memory, where ideas pertinent to the external stimulus at hand are actively processed (Price \& Tewksbury, 1997). Constructs activated by external stimuli are transferred from knowledge store into working memory for conscious process- 
ing (J. R. Anderson, 1983; Price \& Tewksbury, 1997). An important process occurs in this stage, namely that the usability of activated thoughts is evaluated so that thoughts deemed usable for a given judgment are promoted, whereas unusable ones (e.g., inappropriate or irrelevant for a given judgment) are eliminated (Croizet \& Fiske, 2000; Higgins, 1996; Martin, 1986; Price \& Tewksbury, 1997). Thus, "judged usability occurs after knowledge activation but before knowledge use (Higgins, 1996, p. 152, italics in original). For example, a gun-control advocate who reads a news story that raises the self-protection argument may be led to consider that argument, but is likely to dismiss the idea that guns can contribute to the safety of the bearer because it does not align with his or her preexisting attitudes. As the self-protection argument is deemed untenable, irrelevant, or both, the individual's attitude toward allowing concealed handguns remains unchanged, or even reversed as a result of stimulating contradictory thoughts (i.e., boomerang effects). In other words, though activated knowledge has a heightened likelihood of being used in evaluations, its actual use "depends on the knowledge meeting some accuracy criteria rather than its speed or ease of activation or its simple primacy" (Higgins, 1996, p. 162). This long-known, but little-studied subroutine has been alternatively labeled as "judged usability" (Higgins, 1996), "evaluation of construct relevance" (Price \& Tewksbury, 1997), and "usability" (McLeod \& Shah, 2011). The important distinction between activation of knowledge and actual use of such knowledge suggests that people can be seen as "active rather than passive in their use of constructs, once activated" (Price \& Tewksbury, 1997, p. 193; see also Miller \& Krosnick, 2000).

It is important not to confuse applicability of message features to the existing constructs (i.e., applicability) with deemed applicability of activated knowledge to a judgment (i.e., judged usability). Though both phenomena concern relevance of two concepts, the former occurs before knowledge activation, serving as a factor in transferring certain constructs to working memory, while the latter after knowledge activation, regulating whether or not activated construct in working memory can be actually used for a judgment (Higgins, 1996). Unfortunately, however, some scholars simply use "applicability" to refer to two distinct phenomena. For example, Althaus and Kim (2006) defined applicability effects as an instance when "each priming episode generates associations between the primed construct and other constructs, stimuli, or judgmental contexts" (p. 962, italics added). This definition confounds the fit between priming stimulus and existing constructs (i.e., applicability using our term) with the fit between activated construct and a judgment task (i.e., judged usability using our term). Because applicability and judged usability operate at different stages and have different implications for the knowledge activation and use process (Higgins, 1996; Higgins \& Brendl, 1995; Price \& Tewksbury, 1997), scholars should carefully distinguish the two concepts. Therefore, in this article, we use the term "applicability" or "applicable" to refer exclusively to applicability effects before knowledge activation.

Within the framework of knowledge activation and use, agenda setting, framing, and priming are collectively seen as cognitive media effects as each of these models relates to the media's capability of telling people "what to think about" (Iyengar, 1991; Iyengar \& Kinder, 1987; Kosicki, 1993). Specifically, agenda setting effects concern how media messages shape perceptions of what issues people think are important. Framing effects involve the impact of messages on what perspective to think about in understanding issues and events. Priming effects tell people what criteria to think about in making subsequent judgments. Each of these media effects can be viewed in terms of the psychological processes discussed above that illustrate how certain thoughts are generated and used during or immediately after processing external stimuli. Price and Tewksbury (1997) concluded that framing is an applicability effect as salient features of a media message render particular trains of thoughts applicable and activate those thoughts, thereby increasing the likelihood of using them. On the other hand, the researchers argued that priming is an accessibility effect as it concerns the retrieval of a certain activated issue to make subsequent judgments such as evaluating a political leader. They viewed agenda setting as "a particular instance of priming" in that activated issues become retrieved to make judgments about the relative importance of issues (p. 198).

\section{Psychological Mechanisms of Agenda Setting, Priming, and Framing}

\section{Agenda Setting}

While the relevant literature has expanded rapidly, the exact psychological mechanisms underlying the agenda-setting effect have long been assumed rather than empirically tested 
Table 1

Important Terms and Definitions

\begin{tabular}{|c|c|c|}
\hline Phase & Term & Definition \\
\hline Pre-activation & Availability & $\begin{array}{l}\text { The presence or absence of particular knowledge in } \\
\text { knowledge store. }\end{array}$ \\
\hline Pre-activation & Accessibility & $\begin{array}{l}\text { The ease with which available knowledge is retrieved } \\
\text { from knowledge store for activation. }\end{array}$ \\
\hline Pre-activation & Applicability & $\begin{array}{l}\text { The extent to which the attended feature of a message } \\
\text { is consistent with available knowledge in knowledge } \\
\text { store. }\end{array}$ \\
\hline Activation & $\begin{array}{l}\text { Activation (or knowledge } \\
\text { activation) }\end{array}$ & $\begin{array}{l}\text { The process of transferring knowledge from knowledge } \\
\text { store to working memory for conscious processing. } \\
\text { Activation is a function of accessibility and } \\
\text { applicability. Activated knowledge becomes temporarily } \\
\text { accessible from working memory. }\end{array}$ \\
\hline $\begin{array}{l}\text { Post-activation, but } \\
\text { pre-judgment }\end{array}$ & Judged usability & $\begin{array}{l}\text { The process of assessing activated knowledge in terms } \\
\text { of its importance and relevance for a given judgment. }\end{array}$ \\
\hline $\begin{array}{l}\text { Post-activation, but } \\
\text { pre-judgment }\end{array}$ & Evaluation & $\begin{array}{l}\text { Valenced beliefs about activated knowledge (e.g., positive } \\
\text { vs. negative, favorable vs. unfavorable, or true vs. false). }\end{array}$ \\
\hline $\begin{array}{l}\text { Post-activation, but } \\
\text { pre-judgment }\end{array}$ & Importance & $\begin{array}{l}\text { Subjective judgments about the degree to which a } \\
\text { consideration per se is worthy of attention. }\end{array}$ \\
\hline $\begin{array}{l}\text { Post-activation, but } \\
\text { pre-judgment }\end{array}$ & Relevance & $\begin{array}{l}\text { How intrinsically linked a consideration is to the } \\
\text { judgment decision one is about to make. }\end{array}$ \\
\hline
\end{tabular}

(Carpentier, 2014; Kosicki, 1993). The most cited mechanism explaining agenda-setting effects is accessibility bias. Iyengar and Kinder (1987) were among the first scholars to argue that accessibility is responsible for changes in national importance perception. According to this view, issues that receive increasing media coverage tend to be cited as the MIP because those issues become easier to come to mind among others. ${ }^{1}$ In other words, increased activation potential of an issue due to repeated media coverage leads people to cite the issue as the MIP when they are called upon to name the MIP. As a result, the volume of news coverage has been seen as a primary determinant of agenda setting. Many scholars followed suit, suggesting accessibility bias as the primary mechanism for agenda setting. Most notably, Price and Tewksbury

\footnotetext{
${ }^{1}$ Accessibility effect should be distinguished from availability heuristic. The former refers to the state of readiness of a construct in one's working memory for a subsequent activation (Higgins, 1996), while the latter to experienced or estimated ease of retrieval of instances that belong to a certain type of event or class (Tversky \& Kahneman, 1973).
} 
(1997) constructed a theoretical framework in which agenda setting, priming, and framing operate and concluded that agenda setting is an accessibility effect. According to them, agenda setting is an effect in which people cite issues about which they view news stories recently, frequently, or both. Moreover, citing the social cognition literature (Hastie \& Park, 1986; Tversky \& Kahneman, 1973), Scheufele and colleagues (e.g., Scheufele, 2000; Scheufele \& Tewksbury, 2007) argued that agenda setting is a memory-based model, which assumes that people tend to make judgments based on the considerations that are easy to recall. The notion of accessibility bias has since been widely adopted by researchers (e.g., Dearing \& Rogers, 1996; Holbrook \& Hill, 2005; Iyengar, 1991; S.-H. Kim, Scheufele, \& Shanahan, 2002; McCombs, 2004; Sheafer, 2007).

\section{Priming Effects}

Similar to the case of agenda setting, priming effects - an increase in weight accorded to an issue - have long been seen as an accessibility effect. In their initial testing of the priming hypothesis, Iyengar and his associates (Iyengar et al., 1982) speculated that an increase in weight is a product of the increased ease with which people retrieve certain issues from memory, which then can be attributed to an increasing volume of news coverage on those issues. That is, they viewed accessibility bias as a mediator of priming effects. With their speculation having gone unchallenged, similar mechanisms have been suggested as a cause of agenda-setting effects. For example, Price and Tewsbury (1997, p. 197) concluded that "by virtue of its activation, and its direct proportion to the recency and frequency of its activation," a temporarily accessible construct (i.e., a particular issue in the context of priming research) is activated and used as an evaluation criterion when people are called on to evaluate political figures. The accessibility-based explanation has been widely accepted by a range of scholars (e.g., Iyengar \& Kinder, 1987; Kinder \& Sanders, 1996; Mendelberg, 2001; Scheufele, 2000; Scheufele \& Tewksbury, 2007; Valentino, 1999; Valentino, Hutchings, \& White, 2002)

\section{Empirical Evidence Draws the Accessibility} Bias Hypothesis into Question

Scholars have raised a question about the validity of the accessibility-based explanation for agenda-setting and priming effects. For example, Takeshita (2006) argued that conceptualizing agenda-setting and priming effects as an accessibility effect is tantamount to seeing those effects as "an almost mindless, mechanical response based on rote learning from the media" (p.276). Indeed, trivial issues are unlikely to be cited as the MIP or serve as a political evaluation standard simply because they receive media attention or are easily retrievable from memory. For example, if the media pay a lot of attention to a president's propensity to cheat on the golf course, something that may be easily retrieved from memory, we probably would not expect that golf malfeasance would be deemed an important problem or that it would be used to downgrade evaluations of presidential performance.

Shah, Watts, Domke, and Fan (2002) investigated the apparent irony of the rising of President Clinton's approval ratings during his sex scandal and provided indirect evidence that accessibility bias does not explain the phenomenon. Their analysis showed that far greater media attention was paid to the issue than to any other important issues including the economy. Therefore, it might be reasonable to expect that the scandal was the most accessible issue at the time. According to the notion of accessibility bias, when people thought of President Clinton at the time, the scandal must have readily come to mind and the damaging nature of the issue should have undermined his approval rating. However, Shah and colleagues (2002) found that Clinton's high approval ratings were a product of news content "that framed the sex scandal in terms of the actions and accusations of conservative elites, even though this coverage was overwhelmingly negative of Clinton" (p. 366). ${ }^{2}$ These findings suggest that political judgments do not solely depend on the sheer volume of media coverage that results in increased issue accessibility.

In fact, the exclusive focus on the volume of news coverage in agenda-setting and priming research only "strips away

${ }^{2}$ One might argue that Clinton's high approval ratings were a product of the good economy and his favorable presidential performance. However, Shah et al.'s (2002) analyses showed that economic factors such as real disposable income, the valence of economic news coverage, and his presidential performance played a negligible role in encouraging his approval ratings, compared to strategic framing of the scandal. 
almost everything worth knowing about how the media cover an issue and leaves only the shell of the topic" (Kosicki, 1993, p. 112, italics in original). Though some scholars (e.g., Iyengar et al., 1982) argued that increasing news coverage of a problem leads to the substantiating of the importance of the problem, the process may not be as simple as it seems because:

political conflict is not like an intercollegiate debate in which the opponents agree in advance on a definition of the issues. As a matter of fact, the definition of the alternatives is the supreme instrument of power; the antagonists can rarely agree on what the issues are because power is involved in its definition. He who determined what politics is about runs the country, because the definition of alternatives is the choice of conflicts, and the choice of conflicts allocates power. (Schattschneider, 1961, p. 68, as cited in Kosicki, 1993).

That is, looking only at "content-free topic domain, devoid of controversy or contending forces" (Kosicki, 1993, p. 104) does not provide any explanation as to an important interaction between evolution of controversial issues and how the public perceives those issues (Swanson, 1988; Weiss, 1992). From this perspective, "the content-free nature of the issues" that has been the primary focus of the existing agenda-setting and priming research may be a critical flaw in the models (Kosicki, 1993, p. 104).

A growing number of scholars recognize that enhanced accessibility may not be the primary mechanism of agendasetting and priming effects (Takeshita, 2006; Weaver, 2007; Willnat, 1997). At the theoretical level, Takeshita (2006) questioned the validity of accessibility-based explanation for agenda-setting and priming effects. To him, the accessibility bias model misconceptualizes "the transfer of salience" (McCombs \& Shaw, 1993, p. 62) as increased accessibility (e.g., Scheufele, 1999, 2000). Indeed, scholars have used salience to refer to two distinct concepts-the ease of recall and noteworthiness. For example, Higgins (1996) suggested that salience can refer to both something about stimulus materials (e.g., striking images in news stories that draw attention) and readiness of certain thoughts in perceiver's mind (e.g., goals and motivations). Similarly, Young (1992), and Roessler and Eichhorn (1999) argued that salience involves both the perceived importance and the ease of recalling an issue.

There seems to be, however, little reason to see salience as accessibility at least in the context of agenda-setting and priming research. It is reasonable to assume that $\mathrm{McCombs}$ and Shaw (1972) saw issue salience as perceived importance considering the fact that the researchers operationalized issue salience as the most important problem. Takeshita (2006) pointed out that:

McCombs and Shaw (1977) noted a similarity between agenda setting and the status conferral function of the mass media in that both ideas deal with the salience of objects. This suggests that the founders must have meant salience to stand for perceived importance, because the concept of status conferral asserts that the mass media bestow prestige or importance on certain individuals and groups just by paying attention to them. (p. 278)

Empirical evidence that contradicts the notion of accessibility bias has also emerged. For agenda setting, Pingree and Stoycheff (2013) found that repeated presentation of topics without providing the reason why these topics were important did not produce agenda setting for people who had low trust in media gatekeeping. Carpentier (2014) observed the accessibility of the target issue across different types of stimulus materials (including a news story, a related crossword puzzle and a control condition) and found that issue accessibility was enhanced regardless of stimulus types, but agenda setting was observed only when the issue was discussed in news stories. Min, Ghanem, and Evatt (2007) found that people distinguished personal agendas from social agendas among similarly primed issues. Furthermore, scholars (e.g., McCombs \& Weaver, 1973; Weaver, 1977, 1980, 1991) have shown that people with distinct tendencies to seek information about a particular issue displayed different levels of agenda-setting effects. The different agenda-setting effects documented here should not occur if accessibility is a primary driver of the effect, thereby indicating that agenda setting is not a product of "mindless, mechanical response based on rote learning from the media" (Takeshita, 2006, p. 276).

Regarding the roles of accessibility and description of issues in the agenda-setting process, Miller (2007) provided the most direct and compelling evidence. To "manipulate issue accessibility without corresponding content that implies the issue is important" (p. 708), Miller (2007) utilized a word-search puzzle that contains words relevant to an issue. A pilot test showed that conducting a word-search puzzle indeed increased issue accessibility. She compared the content-free (puzzle) condition with the news story condi- 
tions in which news stories provided different interpretations of the current crime rate (i.e., high vs. low crime rate). She found that agenda setting was observed only in the news story conditions and mediated by negative emotions aroused by the stories. Her findings indicate that accessibility is not a sufficient condition for agenda setting as the accessibilitybias explanation suggests.

For priming effects, empirical evidence also contradicts the accessibility bias hypothesis (cf. Valentino et al., 2002). Y. M. Kim (2005) found that despite the prevalence of news coverage favoring military action during the Gulf War, attitude toward a diplomatic solution had more impact on evaluations of the president's handling of the war and the president's overall performance than attitude toward military action. Her findings are aligned with the set/reset model (Martin, 1986), which stipulates that individuals tend to evaluate activated considerations according to certain criteria before actually using them. In a similar vein, Althaus and Kim (2006) found that closely related considerations about the Gulf Crisis exhibited different patterns of priming effects in terms of effect size and direction, though the accessibility of these considerations were stimulated to a similar degree. Their findings showed that the extent to which certain considerations influence political evaluations is more closely related to the tone of news coverage than to the amount of news coverage. This is another piece of evidence challenging the notion of accessibility. Furthermore, Geer (1991) demonstrated that even though the accessibility of important and unimportant issues were equally activated, only issues deemed important were cited as the basis for presidential voting decisions, a form of political evaluation. More directly, Miller and Krosnick (2000) conducted an experiment to assess the role of issue accessibility in priming effects. Their findings showed that increased issue accessibility did not mediate priming effects. Instead, perceived national importance of an issue, derived from the content of news stories, was found to mediate priming effects among those who were both politically knowledgeable and highly trusting of the media. Overall, empirical evidence concern- ing the mechanisms of priming effects provides a strong case against the accessibility-bias hypothesis. ${ }^{3}$

As we discuss in more detail later, there may be no pure accessibility effects in political communication. To quickly reiterate, news stories' typical functions of highlighting and substantiating a consideration inevitably affect both accessibility and judged usability of the consideration that is being discussed. However, it is also noteworthy that not all individuals are motivated or able to judge the usability of activated constructs. Because judged usability "involves a controlled process" (Higgins, 1996, p. 152), people lacking motivation and ability may be more likely to rely on accessible constructs from working memory when making judgments (see Devine, 1989; Kruglanski, 1989). Therefore, the relative weights of accessibility and judged usability of activated constructs can vary.

\section{Mechanisms of Framing Effects}

Like agenda setting and priming, framing was once seen as an accessibility effect (Druckman, 2001a). For example, Chong (1993), Iyengar (1991), and Zaller (1992) argued that the extent to which certain considerations are easy to recall is the primary determinant of framing effects. Unlike agenda setting and priming, however, the accessibility-based explanation for framing effects has been retired relatively quickly as theoretical (e.g., Price \& Tewksbury, 1997) and empirical evidence (e.g., Nelson, Oxley, et al., 1997) suggests that framing effects are a product of how issues are described in a communicating text.

Framing effects operate on multiple levels including availability, activation, and use of activated considerations (Brewer, Graf, \& Willnat, 2003; Chong \& Druckman, 2007b). The presentation of alternative considerations about an issue in a communicating text renders those considerations available in perceivers' minds, a process tantamount to learning (Chong \& Druckman, 2007b). Newly learned or existing considerations become activated and, as a result, become accessible by the virtue of the active processing of

\footnotetext{
${ }^{3}$ Besides the debate over the accessibility bias hypothesis, two alternative explanations for classic media priming hypothesis have been proposed. Lenz (2009) argued priming effects, which is typically operationalized as a weight increase of an issue, is a product of learning and adopting preferred parties' positions on issues. On the other, Hart and Middleton (2014) proposed the projection hypothesis, arguing that "news causes voters to align their overall approval with issue approval" (p. 582). In the latest study, Takens, Kleinnijenhuis, Van Hoof, and Van Atteveldt (2015) argued that media priming is not an artifact of learning or projection.
} 
stimuli such as news stories (Price and Tewksbury, 1997). Sustained emphasis and justification of these considerations, in turn, makes them particularly usable for judgments about the issue in question (Nelson, Clawson, \& Oxley, 1997; Nelson \& Oxley, 1999; Nelson, Oxley, et al., 1997).

More specifically, message frames can induce thoughts that correspond to the perspective primarily featured in the message. For example, Price et al. (1997) conducted an experiment in which students were randomly assigned to read a news article about proposed state funding cuts for public universities in the region. With the facts being identical, each story highlighted different aspects of the plan such as conflict between citizen groups over the plan and the resultant tuition increases. The content-analysis of respondents' thoughts showed that their attention was "directed away from core story elements [i.e., planned funding cuts] and toward ideas related to the frame in question" (Price et al., 1997, p. 494 , italics in original). Similarly, Shen (2004) found that political ads highlighting issue positions evoked more issuerelated thoughts than thoughts pertaining to character, while character-framed political ads had the opposite effect. Importantly, these framing effects were so robust that framecorresponding thoughts were activated even when the rival thoughts were highly accessible from memory.

When thoughts are generated by message frames, they appear to carry a specific evaluative implication in such a way that certain beliefs are perceived to be more important than before. This process can be expressed in an algebraic formula derived from expectancy value model of attitudes (Fishbein, 1963):

Attitude $=\sum v_{i}^{*} w_{i}$, where $v_{i}$ is the evaluation of the object on attribute $i$, and $w_{i}$ is the salience weight $\left(\sum w_{i}=1\right)$ associated with that attribute (Chong \& Druckman, 2007b, p. 105).

Applying this model to attitude formation regarding welfare policy, Nelson, Oxley, et al. (1997) observed that the coefficient of beliefs about individual causes of poverty (e.g., lack of effort and thrift) increased in one's attitude about welfare policy when people saw a news story emphasizing that people on welfare do not deserve special treatment. In other words, message frames make a certain belief play a more important role in subsequent judgments by increasing perceived importance of the belief (see N. H. Anderson, 1981). In an attempt to formally test the mediating role of perceived importance in the framing processes, Nelson and colleagues (e.g., Nelson, Clawson, et al., 1997; Nelson \& Oxley, 1999) demonstrated that changes in belief importance produced by message frames explain shifts in people's attitudes toward the issue in question. The researchers also found that belief accessibility did not mediate framing effects.

Also noteworthy is the distinction between framing effects and persuasion, both of which concern changes in attitudes or opinions. Nelson and colleagues (e.g., Nelson, Clawson, et al., 1997; Nelson \& Kinder, 1996; Nelson \& Oxley, 1999; Nelson, Oxley, et al., 1997) argued that attitude change can take place in two ways: altering the importance of an existing piece of information about an attitude object or directly changing the belief about an attitude object (e.g., from positive to negative). Aligning with Cohen's (1963) insight that the media are successful at "telling people what to think about" (p. 16), they argued that the former constitutes framing effects in that a stimulus influences one's attitude indirectly through changes in perceived importance of certain existing considerations, while the latter represents persuasion in that a communicating text directly changes one's attitude toward an attitude object. Supporting this view, Nelson, Oxley and Clawson's (1997) experimental results showed that citizens' tolerance of a racist group's rally was shaped by which considerations they weighed more. Specifically, those exposed to a news story describing the rally as the disruption of public order accorded more importance to corresponding considerations in evaluating the event.

Although Nelson and colleagues' series of experiments generally support their argument that framing works through belief importance rather than belief change, when belief importance and belief change were assessed together in predicting attitude change, belief change had small but discernable effects on attitude change (Nelson \& Oxley, 1999). Slothuus (2008) reconciles the discrepancy by taking into account perceivers' political knowledge. His findings showed that for those who were politically knowledgeable, framing effects were mediated by perceived importance of available considerations, while framing effects were mediated by both belief importance and belief change among people with moderate political knowledge. That is, framing effects are more likely to be pronounced among the politically knowledgeable, while persuasion is more common among those who are less politically sophisticated. 


\section{Redefining the Relationships among Agenda Setting, Priming, and Framing}

We begin this section by noting the difference between priming effects in social psychological studies and priming effects in mass communication research. To obviate possible confusion, we now refer to priming studied in the context of mass communication as "media priming" and priming in social psychology as "simple priming."

Priming effects in social psychological studies are primarily an accessibility effect as a priming event ostensibly unrelated to a subsequent judgment increases accessibility of a certain construct without imbuing other judgmental attributes (Chong \& Druckman, 2007b; Druckman, 2001b). For example, simple priming occurs when experimental participants are asked to memorize either positive or negative trait terms (i.e., priming event) such as self-confidence or conceited, and then are asked to judge an ambiguous behavior of another person that can be construed either way. The main finding is that it is a construct's residual energy retained from the priming event (i.e., increased accessibility of positive or negative trait terms) that subconsciously influences the judgment of an unrelated event that follows (i.e., ambiguous behaviors) without being confounded by any other attributes that may transfer from a priming stimulus.

However, media priming is different from simple priming with respect to the nature of a priming stimulus and, more importantly, the priming mechanism. As noted by Chong and Druckman (2007b), presenting news stories with a sustained emphasis on and substantiation of a consideration is fundamentally different from having people memorize words that are apparently unrelated to a judgment task. The media accounts that serve as priming stimuli often provide cues to issue importance, thereby justifying the use of the issue at hand as a political evaluation standard. Simply, the fact that the media would cover the issue at all conveys the notion that the issue is important to some extent. In some cases, a journalist might bring the object of a subsequent judgment, such as a politician, into the story in the process of covering an issue. Moreover, journalists are often trained to include information to substantiate the importance, significance, or implications of the issue being addressed. This practice creates a more direct linkage between news stories and subsequent judgments of evaluating political figures than one would typically observe in simple priming studies. That is, the issues presented in the priming news story are more likely to be used as political evaluation standards, not only because they are made more accessible, but also because the messages render them more suitable for political judgments by reinforcing their importance or relevance. In other words, there really are no pure accessibility effects in political communication. In sum, the ostensible irrelevance between priming events and subsequent judgments does not typically apply to media priming contexts.

When it comes to the mechanisms of media priming, we noted above that the notion of an accessibility effect neither consistently explains real-life situations, nor receives empirical support. The largely negative coverage of President Clinton during Lewinsky scandal did not hurt the president's approval ratings (Shah et al., 2002). Moreover, Miller and Krosnick (2000) found that it is people's inference of national importance of issues from news coverage that led people to evaluate the president based on the issues. Likewise, Althaus and Kim (2006, p. 960) concluded that media priming effects are a product of creating associations between highlighted issues and political leaders to be evaluated rather than merely increasing accessibility of issues. These findings suggest that increased suitability of a primed consideration for subsequent judgments (i.e., increased judged usability) is the locus of media priming effects (see also Nelson \& Oxley, 1999; Nelson, Oxley, et al., 1997).

Our conclusion, that media priming is not an accessibility effect, leads to the revision of the relationships among agenda setting, framing, and media priming as suggested by Price and Tewksbury (1997). Although framing can operate on three fronts by a) making certain considerations available, b) making available and corresponding considerations accessible, and c) making certain considerations more suitable for a given judgment (Chong \& Druckman, 2007b), it is the rendering of a particular consideration relatively important, relevant, or both to a judgment through which framing effects work (Nelson \& Oxley, 1999; Nelson, Oxley, et al., 1997). Therefore, it can be concluded that framing is a combination of an applicability and a judged usability effect. An applicability effect occurs as media emphasis on a certain perspective increases the likelihood of activating corresponding thoughts. A judged usability effect takes place as media messages provide information substantiating the perspective so that the individual can evaluate the utility of activated thoughts for a judgment task, provided that the perceiver has adequate motivation and ability to do so. Judged usability also relates to the evaluation of a set of activated thoughts 
in the process of selecting the most suitable thought for a given judgment (see Figure 1 for the illustration of framing processes). Overall, framing not only selectively activates a particular set of thoughts that resonate with the salient message features, but also provides information, which can regulate the weight attached to those thoughts in the form of, for example, perceived importance, relevance, or both, thereby determining the use of them for a given judgment.

Given the fact that framing and media priming share the same stimulus materials, media priming may intervene in the same cognitive processes as framing, but is only probed by a different dependent variable (Entman, 2007). Therefore, media priming may also be best conceptualized as a combi- nation of an applicability and a judged usability effect. Media coverage of an issue increases the likelihood of activating thoughts related to the issue by actively discussing it (i.e., applicability effect). Simultaneously, news stories typically tell people that the issue is something to be concerned about by directly or indirectly suggesting its significance and consequences relevant at the individual, local, state, or national levels. As politicians are expected to address locally and nationally important issues, the issues that the media portray as important are likely to serve as judgment standards when people are asked to evaluate the performance of politicians (see Figure 2 for the illustration of agenda-setting and media priming processes). That is, a primed issue is used as a

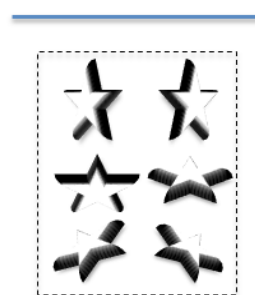

Pool of potential aspects

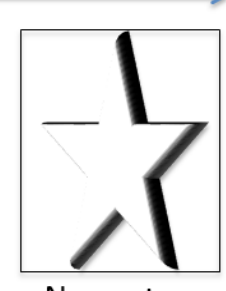

News story

\section{News framing}

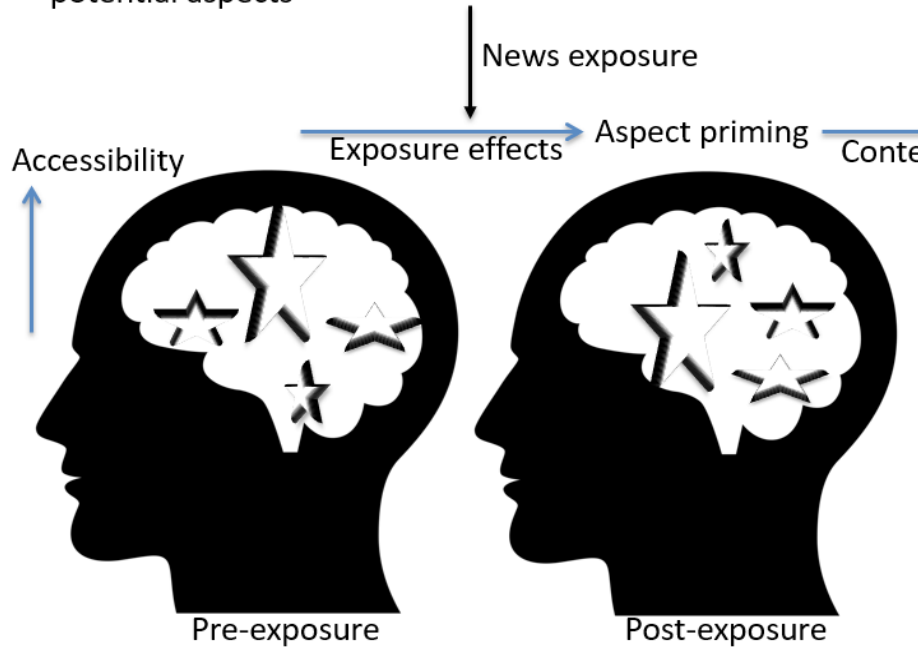

\section{News exposure}

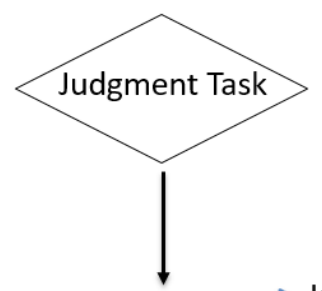

Size: Importance (large=important)

Shade: Relevance (bright=relevant)

Increased JU

Judgment outcomes

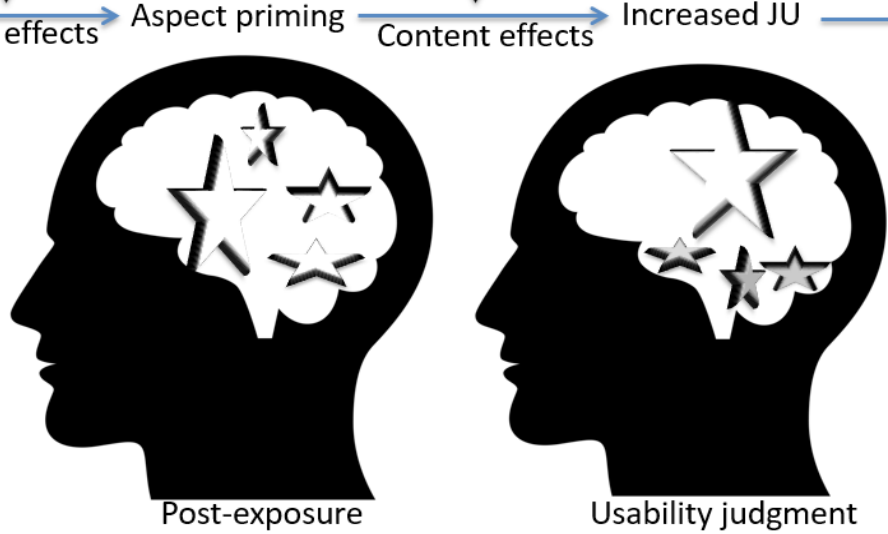

Framing outcome

(e.g., policy or individual/ group perceptions)

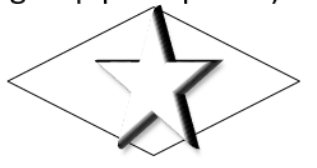

Figure 1. Framing Processes. The news framing process illustrates that among different aspects of an issue (i.e., stars with different angles), a certain aspect is chosen over others to characterize an issue or event. For example, the issue of unemployment is described in terms of the cheap labor provided by immigrants (i.e., the star facing left). Exposure to the news story activates thoughts correspond to immigrants (i.e., the rising left-facing star) rather than thoughts related to other aspects of the issue (e.g., legislation, education, and cheap imports from China) and, at the same time, makes the former thoughts prominent by promoting their importance (i.e., growing size of the left-facing star) and relevance (i.e., bright shade of the star) to the understanding of the issue at hand. That is, issue perceptions are influenced by the consideration featured in the news story. Thoughts related to neglected considerations become relegated to the degree that thoughts about a featured consideration are magnified. Note that judged usability may not come into play in the transition from pre- to post-exposure as relevance judgment can only be made when a target judgment is given. 
political evaluation standard to the extent that it is deemed appropriate to be employed to judge a politician (Geer, 1991; Miller \& Krosnick, 2000). As the weight the media place on an issue transfers to the weight people place on it as political evaluation standards, media "[p]riming, then, is a name for the goal, the intended effect, of strategic actors' framing activities" (Entman, 2007, p. 165).

For agenda setting, the evidence reviewed above suggests

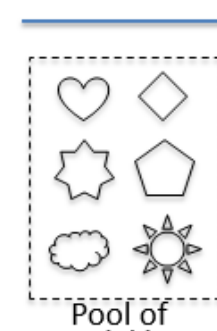
potential issues
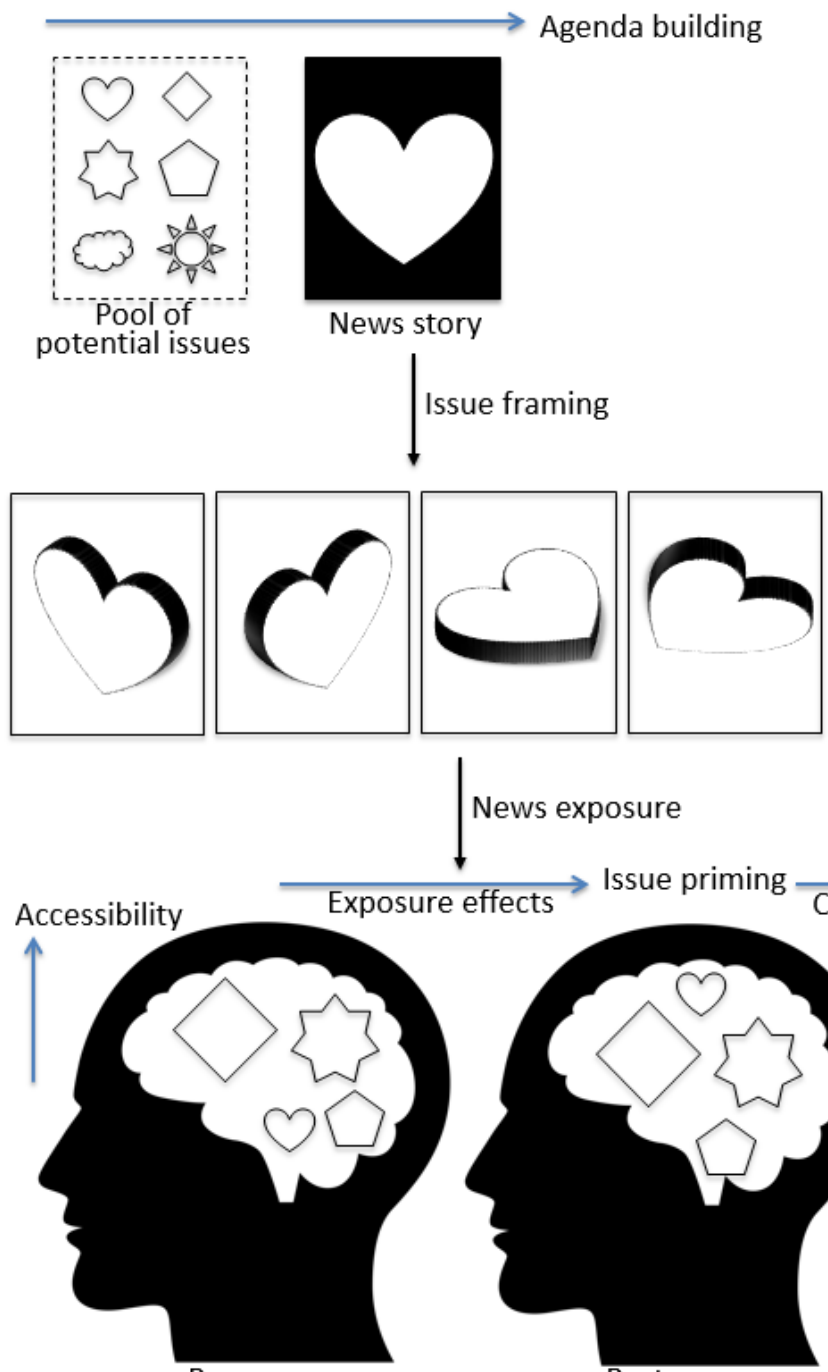

Pre-exposure

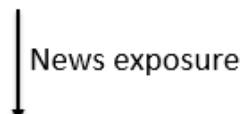

building

$\longrightarrow$ Issue priming

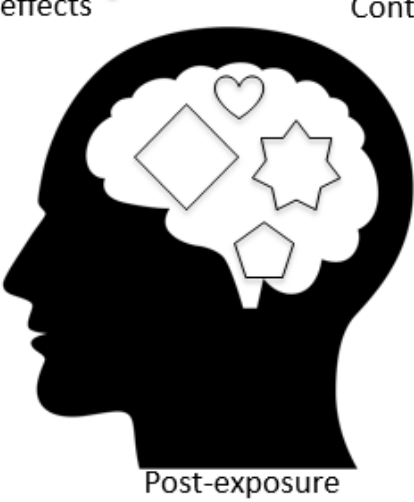

\section{Agenda setting/media priming Processes}

Size: Importance (large=important)

Shade: Relevance (bright=relevant)

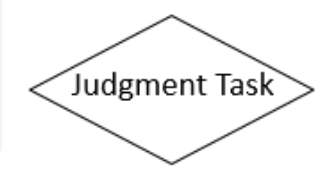

$\overrightarrow{~ n t ~ e f f e c t s}$

Increased JU

Judgment outcomes

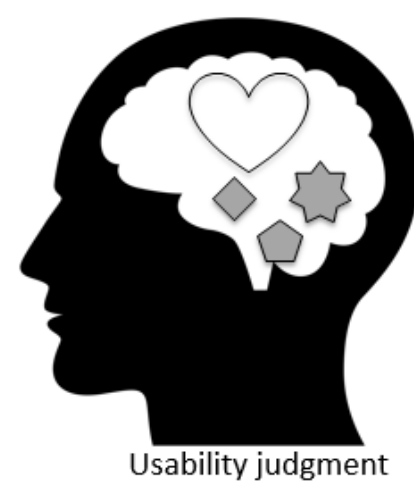

Agenda setting outcome (e.g., most important problem)

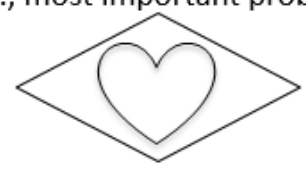

Media priming outcome (e.g., presidential evaluation)

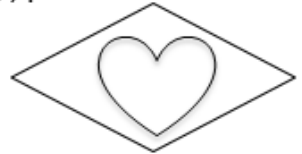

Figure 2. Agenda-setting and Media Priming Processes. The agenda building process illustrates that news media selectively features a certain issue. The issue framing process shows that the same issue can be viewed from different perspectives (e.g., unemployment is explained in terms of either immigrants, legislation, education, or cheap imports from China). Typically, news media uses a frame to justifies the chosen issue as worthy of public attention. In other words, for example, regardless of frames of news stories about unemployment, people are likely to perceive that the issue deserves closer attention. The transition from pre-exposure to post-exposure shows that, upon exposure to stories about an issue, existing thoughts corresponding to the featured issue are activated and become elevated in terms of "top-of-mindedness" (i.e., the rising heart). At the same time, the activated thoughts become important to the extent that the news story substantiate the chosen issue and, therefore, become relevant to judging what most important problem is or assessing how the President performs her/his job. Concurrently, unrelated thoughts are relegated, as they are overlooked, in their importance and relevance to the degree that the activated thoughts are magnified. Note that judged usability may not come into play in the transition from pre- to post-exposure as relevance judgment can only be made when a target judgment is given. 
that it is what the messages convey about an issue that produces agenda-setting effects just like framing and media priming effects do. In this sense, "[a]genda setting can thus be seen as another name for successfully performing the first function of framing: defining problems worthy of public and government attention" (Entman, 2007, p. 164, italics in original).

Above, we cited Entman (2007) to define the relationships among agenda setting, framing, and media priming. Our intention to do so was not to argue that one type of effects subsumes the others, but to illustrate that those effects are closely related to one another, while surveying different types of judgments. News stories emphasizing a certain perspective or an issue inevitably bring corresponding thoughts to mind. At the same time, the focal perspective or issue is imbued with properties such as relative importance, relevance, and particular emotions to the extent that the content of the stories promote such attributes. When judgment tasks such as MIP perceptions and political evaluations are given, a consideration with higher values is likely to play a more pivotal role in shaping a given judgment. Therefore, framing and media priming are theoretically indistinguishable as they share underlying cognitive processes (Chong \& Druckman, 2007b, 2007a; Entman, 2007, 2010). Likewise, agenda setting and media priming are two of a kind in that both of the effects are a product of news media's conventional practices of portraying issues as deserving particular attention, while differing largely in terms of the subsequent judgments made (Entman, 2007). Accordingly, it can be concluded that framing, media priming, and agenda setting share common cognitive processes as a result of the nature of news reporting, albeit "scholars often seem to choose among the three terms based less on theoretical distinctions among them than on the dependent variable of interest" (Entman, 2007, p. 171).

\section{The Judged Usability Model}

In this section, we propose the Judged Usability Model. The conclusion we made earlier, that is, framing and media priming "share common processes, and the two terms can be used interchangeably" (Chong \& Druckman, 2007b, p. 115), implies that the Expectancy-value Model of attitudes (Fishbein, 1963) that some scholars (e.g., Chong \& Druckman, 2007a, 2007b; Nelson, Oxley, et al., 1997) have used to explain framing effects can also explain media priming effects. That is, because evidence indicates that they are the same kind of effects with different names, a known mechanism underlying one effect can be applied to the other.

We add to that model by incorporating the concept of judged usability to specify elements that can determine the use of a consideration for a given judgment.

We begin with the following attitude formation formula: Attitude $=\sum v_{i}{ }^{*} w_{i}$, where $v_{i}$ is the evaluation of the object on attribute $i$, and $w_{i}$ is the salience weight $\left(\sum w_{i}=1\right)$ associated with that attribute (Chong \& Druckman, 2007b, p. 105).

Applying this model to the example of attitude formation regarding a public rally by white supremacists, we might expect that at least two considerations to arise (e.g., free speech as $v_{1}$ vs. public disturbance as $v_{2}$ ). When these two considerations oppose each other, an individual's attitude toward the object (in this case the rally) depends on the relative weights (i.e., $w_{i}$ ) given to each attribute. Indeed, Nelson and his collaborators (Nelson, Clawson, et al., 1997; Nelson \& Oxley, 1999; Nelson, Oxley, et al., 1997) demonstrated that attitudes are shaped by an attribute that receives a greater weight in the form of perceived importance.

Applying the formula to media priming effects, media messages highlight certain considerations that assume the position of $v_{i}$ in the attitude formula. By calling attention to certain considerations, messages influence the relative weights given to considerations in making subsequent judgments. For example, an issue featured in news stories may play a more important role than before in making political evaluations as the stories substantiate the importance of the issue. The formula suggests that while weights determine the relative value of competing judgment considerations, they also act as a gatekeeper to control the fate of activated considerations. Even if a consideration is brought to mind as it is featured in media messages, the consideration may not be able to play a role when it receives no weight. As such, simple activation of a consideration may not be sufficient to increase its weight in subsequent judgments. Two additional factors beyond simple media attention are likely to come into play: evaluative media content regarding the consideration and judgments about the appropriate weight of the consideration made by the message receiver.

First, just as message information that supports a particular consideration can increase the weight attached to it (see Miller \& Krosnick, 2000; Nelson \& Oxley, 1999; Nelson, 
Oxley, et al., 1997), the consideration that is discredited is likely to lose weight to the point where it becomes nil, which in turn eliminates that consideration from a mental calculus. That is, a message may implicitly or explicitly attack the importance of a given consideration. Simply put, messages may influence whether and how a certain consideration is used in forming attitudes and making evaluations through selective emphasis and varying degrees of substantiation.

Second, the premise that weight determines the fate of activated considerations aligns with the concept of judged usability. Scholars have noted that among thoughts that are activated, only those deemed appropriate (or relevant) to a judgment (i.e., those that have sufficient judged usability) are used to shape that judgment, while others are disregarded (Higgins, 1996; Higgins \& Bargh, 1987; Price \& Tewksbury, 1997). This gatekeeping process "occurs after knowledge activation but before knowledge use" (Higgins, 1996, p. 152, italics in original). For example, with equal knowledge of African American pejorative stereotypes, lowprejudice white individuals were less likely to exhibit such beliefs than high prejudice subjects when they were primed with racial stereotypes (Devine, 1989). In this case, the predispositions of low-prejudice individuals suppressed the activated considerations when making subsequent judgments. Motives and goals can also act as a mental filter that regulates judged usability of activated thoughts. For example, priming a fear of invalidity led people to avoid the immediate use of activated thoughts and seek alternatives (Kruglanski, 1989). Overall, the characteristics of judged usability are squarely aligned with the function of weight in the attitude formation formula discussed above, that is, determining the perceived utility of an activated consideration in judgmentmaking process.

Based on our observation that the fate of activated considerations is malleable, we propose "The Judged Usability Model" by incorporating the concept of judged usability to further specify elements that can determine the fate of considerations. This model is based on the attitude formation formula discussed above (i.e., Attitude $=\sum v_{i}{ }^{*} w_{i}$ ). However, we incorporate judged usability $\left(U_{i}\right)$ as the weight component $\left(w_{i}\right)$. We also use the label $E_{i}$ in the place of $v_{i}$ to denote the evaluation of the judgment target using each usable consideration. Again, the way we incorporate $U_{i}$ as the weight component $\left(w_{i}\right)$ in the consideration attitude allows for the possibility that unusable considerations can be eliminated in the winnowing process of making judgments (i.e., $U_{i}=0$ )
(Devine, 1989; Higgins, 1996; Kruglanski, 1989). Our conceptualization also aligns with the notion that attitude is a summary evaluation of beliefs that are germane to the attitude object (Chong \& Druckman, 2007b; Nelson, Oxley, et al., 1997). Our adapted judgment formula is as follows:

Judgment $=\sum U_{i}{ }^{*} E_{i}$, where $U_{i}$ is the judged usability of consideration $i$, and $E_{i}$ is the evaluation of the target on consideration $i$.

Our model implies two opposite routes that a given consideration can take in the judgment making processes. A consideration can exert greater influence to the extent that it is deemed usable and the evaluation of the target judgment becomes more extreme (either positive or negative). Alternatively, if either of those values is close to nil, the consideration is nullified. Such situations might result from a consideration that is deemed unusable (e.g., President Obama's preference for St. Louis-style pizza over Chicagostyle pizza) or if the target is evaluated as being neutral or unknown (e.g., either president's handling of the economy is seen as being neither positive nor negative or the individual does not have enough information to make a judgment), in each case causing the given consideration to be inapplicable to the targeted judgment (e.g., the evaluation of the president's performance).

This Judged Usability Model can be more readily observed in the conscious mental calculus that people use to make high involvement decisions like buying a new car. In such high involvement situations where there are greater personal relevance and consequences (Petty \& Cacioppo, 1979), people are motivated to exert considerable mental effort into making the judgment (Chaiken, 1980). This judgment process may begin with an active attempt to identify relevant considerations (e.g., price, fuel efficiency, drive type, safety features, convenience features, options, and packages). For each candidate car, individuals then rate each criterion in terms of how good or bad a certain feature is (e.g., good vs. bad fuel economy) and how important the feature is (e.g., fuel economy and convenience features may not be important for those looking for a sports car). As high involvement situations like this are conducive to generating more topicrelated thoughts (Petty \& Cacioppo, 1979) and evaluating given evidence more thoroughly (Chaiken, 1980), the complexity of the judgment formula and the mental effort required to come to a conclusion depend on the level of issue involvement. While individuals do not often take the additional step of quantifying each of these evaluations and 
aggregating them to make the purchase decision, the above equation may to some degree represent the judgment process used in such high involvement decisions.

Of course, most of the decisions that individuals make on a daily basis are low-involvement decisions that lack the necessary motivation to engage in exhaustive evaluations. Such situations may be much simpler in several respects. For instance, they may involve identifying fewer considerations and less effortful evaluation of them. The judgment process may be less conscious and more automatic, and individuals may resort to more simple and efficient heuristic shortcuts to make judgments. The distinction between such high and low involvement judgment situations is represented in the central vs. peripheral routes to the persuasion in Petty and Cacioppo's Elaboration Likelihood Model (Petty \& Cacioppo, 2012) and the heuristic vs. systemic information processing of Chaiken's (1987) Heuristic-Systematic Model. Though high and low involvement judgments may vary in terms of the number and nature of considerations used, as well the effort and strategies used to make decisions, we still argue that judgments are made by some level of assessment of at least one consideration.

\section{Judged Usability Standards}

\section{Importance and relevance.}

The judged usability of a consideration itself is also a composite judgment. Among many possible standards of judged usability (Croizet \& Fiske, 2000), our model stresses the two attributes that media messages may affect (N. H. Anderson, 1981; Nelson, Oxley, et al., 1997; Van der Pligt \& Eiser, 1984): the perceived importance of a consideration $\left(I_{i}\right)$ and its relevance to the judgment at hand $\left(R_{i}\right)$. Perceived importance refers to subjective judgments about the degree to which a consideration per se is worthy of attention. Relevance indicates how intrinsically linked a consideration is to the judgment decision one is about to make. We can illustrate this point by transforming the original judgment equation that we posed above as:

Judgment $=\sum I_{i}{ }^{*} R_{i} * E_{i}$, where $I_{i}$ is the perceived importance of consideration $i, R_{i}$ is the perceived relevance of consideration $i$. and $E_{i}$ is the evaluation of consideration $i$.

These two components of consideration usability are to some degree independent. For example, the fact that Japan in- vaded many Asian countries and committed numerous war atrocities during the World War II can be generally seen as something to be worthy of attention. However, when the Japanese acts of aggression are contemplated in the context of a car-buying decision, they may not be seen as intrinsically relevant to the decision about whether or not to buy a Japanese car. By contrast, the consideration that the automobile in question comes standard with cargo netting is intrinsically relevant in the sense that cargo nets come into play in the day-to-day use of the car, but the cargo netting may be seen as an unimportant feature. To be applicable to the car-buying decision, a consideration must be both important and relevant (e.g., high fuel efficiency or reliability ratings).

Also noteworthy is that the assessment of these elements is subjective in nature and thus will vary from person to person. In the above example, consumers in Korea and China, two of many countries that were devastated by the Japanese invasion, are more likely to assign higher values to both perceived importance and relevance of the historical facts than consumers in South America, where Japanese colonialism had virtually no influence.

Findings illustrate that these attributes can play a role in winnowing unusable considerations. Perceived importance was found to filter unimportant issues in the context of evaluating presidential performance. Miller and Krosnick (2000) demonstrated that influence of issue considerations on presidential performance evaluations was a function of how important those issues were perceived to be. More directly, Geer (1991) found that only issues deemed important were cited as the basis for presidential voting decisions, even though important and unimportant issues were equally primed.

Similarly, a consideration perceived to be irrelevant to the judgment at hand may fail to receive further consideration. Although not designed to demonstrate the effect of perceived relevance on usability judgments, Matthes (2006) found that the perception of irrelevance prevents further attention to the irrelevant issues (see also McCombs, 2004). These findings illustrate that the suggested elements can function as a filter that screens out activated considerations that do not have utility for a target judgment.

\section{Evaluations.}

Evaluations refer to valenced beliefs involving a given consideration (e.g., positive vs. negative, favorable vs. 
unfavorable, or true vs. false). Presidential performance judgments, for example, consist of a combination of positive and negative evaluations of the president's economic stewardship, foreign-policy performance, and the like. In the judgment formula presented above (i.e., Judgment $=\sum U_{i}{ }^{*} E_{i}$ ), the usability standards and evaluation are multiplied in a way that if either component is essentially nil, a consideration becomes inapplicable to a judgment. Thus, even if a consideration is deemed usable, one has to have an evaluation of the consideration in order to apply it to a given judgment. This may involve two somewhat related processes: a) people should have evidence on which they can evaluate a consideration, and b) be reasonably certain that their evaluations are sufficiently valid.

Evidence (e.g., factual claims, past experience, and inferences from predisposition or values) enables people to form evaluations about a given consideration that has the functional value of making decisions with less evaluative effort (Fazio, Blascovich, \& Driscoll, 1992). Conversely, the absence of evidence may force individuals to extend greater effort to make the evaluation "on the spot," which may cause people to simply turn to alternative considerations for which evaluations are readily available instead of investing their time and energy to establish one (Schuman \& Presser, 1980; see also Zaller, 1992). Furthermore, considerations remain unevaluated may have no utility for future judgments. For example, if one is unable to evaluate the "life begins at conception" consideration in terms of whether it is true or false, that consideration does not provide any evaluative direction for a judgment about whether abortion should be legal, and thus is likely to inapplicable to that judgment.

In light of factors like available evidence, past experience, and value predispositions, individuals need to feel assured, at least to some degree, that their evaluative beliefs are valid enough to guide a given judgment. Possessing dubious evaluations may make people less inclined to make judgments based on those evaluations (cf. Croizet \& Fiske, 2000). As such, creating uncertainty about an evaluative belief may take a significant toll on the utility of that belief. Evidence suggests that an ambivalent attitude causes individuals to avoid making decisions (Hänze, 2001; Jonas, Diehl, \& Brömer, 1997) or to seek alternative grounds for a given judgment (Luce, Bettman, \& Payne, 1997). Thus, for example, people who think both sides of the abortion issue make reasonable claims as to when human life begins (e.g., life begins at conception vs. life begins after the fetus is vi- able outside the womb), but who are unable to make a satisfactory judgment about which side is correct may find it hard to base their abortion position on the "life begins" consideration. As a result, alternative considerations that can provide more definitive implications are likely to be sought.

\section{Judgment Certainty}

The judgment components discussed above have their own levels of certainty. People form a belief about a judgment object with a certain level of confidence (Fischhoff, Slovic, $\&$ Lichtenstein, 1977). The more certain one is about a judgment object, the smaller the latitude of acceptance the person has to a set of ideas different from her own (Sherif \& Hovland, 1961). Thus, the level of certainty reduces the scope within which potential message effects can operate.

In terms of the mode of information processing, a sense of uncertainty can lead to systematic information processing (i.e., thorough consideration of message arguments; see Chaiken, 1980), thereby increasing potential message effects. By contrast, a sense of certainty seems to encourage using superficial shortcuts during information processing (i.e., heuristic processing). For example, Tiedens and Linton (2001) found that people who experienced certainty were more likely to process information superficially, relying on the expertise of a source and stereotypes, whereas those who felt uncertainty were more likely to be affected by argument quality. In the above contexts, uncertainty is a situational characteristic. However, tolerance for uncertainty, a more stable personality trait, may also come into play to influence strategies used to reduce uncertainty. Individuals who are high in tolerance for uncertainty tend to favor systematic information processing strategies, while those high in need for closure gravitate toward heuristic processing (Kruglanski, Dechesne, Orehek, \& Pierro, 2009).

While uncertainty provides room for a communicating text to have intended effects, media messages can also create uncertainty. Researchers have noted that journalists, following the canons of objectivity, often report both sides of a social or scientific controversy even in situations when the preponderance of evidence supports one side. For example, Gelbspan's (1998) study of the global warming controversy found that media messages gave equal attention to minor opinions as much as the scientific consensus. Similarly, Dearing's (1995) content analysis of news stories regarding fringe scientific theories such as an alternative cause of 
AIDS and cold fusion illustrates that maverick scientific theories that contradict predominant scientific findings were lent credibility by journalists. Findings suggest that such a treatment by the media can breed the sense of uncertainty about a given issue (Corbett $\&$ Durfee, 2004), which then opens one up to media effects. In fact, this may explain the persistence of discredited beliefs such as the denial of global warming or the belief in the link between childhood vaccinations and autism.

\section{Message Effects and the Judged Usability}

Messages may influence judgments by actively raising or lowering a consideration's judged usability by addressing the importance and relevance of a given consideration. In the case of presidential performance evaluations, a message may stress the importance (or unimportance) of the economy. The message may also address the relevance of the economic consideration by making the case that the president plays a significant role (or insignificant, for example, by suggesting that important elements and factors of economic success are beyond the president's control) in guiding the health of the economy.

The findings of previous studies indicate that media messages can be successful in altering the importance and relevance elements by presenting interpretations of an issue that revolve around the chosen consideration (e.g., Krosnick \& Kinder, 1990; Miller \& Krosnick, 2000; Nelson, Clawson, et al., 1997; Nelson \& Oxley, 1999; Nelson, Oxley, et al., 1997). For example, Nelson and Oxley (1999) demonstrated that news story frames shaped audience understanding of an urban development plan by highlighting the importance and relevance of either economic or environmental considerations. Of course, news frames may also be substantiated by frame-consistent facts that address the certainty component of judged usability and thereby gaining additional influence. Thus, framing effects operate by activating the featured consideration inherent in the frame, making it more likely to be deemed important and relevant, and in some cases more certain, elevating that consideration's role in subsequent judgments (e.g., Nelson, Clawson, et al., 1997; Nelson \& Oxley, 1999; Nelson, Oxley, et al., 1997).
On a related note, media messages may encourage people to assess the usability of activated considerations, for example, by providing information that is useful for the evaluation, that relates people to the issue that is being discussed, or both. That is, for example, a news story that addresses the importance and relevance of the featured consideration for a judgment can be facilitative of judging usability of the consideration by reducing the need for seeking further information or inferring it from the facts provided. Similarly, a news story that hints at an issue's impact on people (e.g., alluding to the impact of a naval port construction on sea farming) may invite them (e.g., sea farmers) to ruminate on relevant considerations. In this sense, judged usability could be a media effect.

Regarding evaluations, a great deal of empirical evidence indicates that evaluative beliefs about a consideration can be shaped in line with central ideas of a communicating text (Chaiken, Wood, \& Eagly, 1996; Nelson \& Oxley, 1999; Page $\&$ Shapir, 1992). If a news story about a regional development plan is framed in environmental impact terms, for example, people's evaluations about environmental impacts of the plan become pessimistic (Nelson \& Oxley, 1999). Such changes in the content of evaluation result from the merits of information substantiating arguments presented in a media message and the appreciation of the merits by the audience (Eagly \& Chaiken, 1993; Petty \& Cacioppo, 2012; Zaller, 1992). That is, factual information provided by the messages has the potential to serve as a basis of the content of an evaluation (Danes, Hunter, \& Woelfel, 1978; Nelson, Oxley, et al., 1997).

\section{Reverse Agenda Setting and Reverse Priming}

The conclusion we made above that media messages can regulate judgment components (i.e., importance, relevance, and evaluation) leads to another important implication: Just as news messages can promote the use of a given consideration in subsequent judgments, they may also suppress a given consideration such that it is less likely to be named as the MIP (i.e., reverse agenda setting) or serve as a political evaluation standard (i.e., reverse priming) than the baseline. ${ }^{4}$

\footnotetext{
${ }^{4}$ Some scholars (e.g., Dodel, Comesaña, \& Blanc, 2019) use the term reverse-agenda setting to refer to a reverse causation of agenda setting (e.g., the public set agendas for political elites). For the lack of a better term, we use the term reverse to refer to reducing the likelihood of using a consideration for a given judgment.
} 
These potential cognitive effects that expand traditional conceptions of agenda-setting and priming effects may occur in response to three different journalistic practices: a) ignoring a particular consideration (i.e., omission); b) accentuating other competing considerations (i.e., distraction); and c) attacking the viability of a potential consideration (i.e., trivialization). Examples of such practices can be found in McLeod and Hertog's (1999) discussion of media coverage of anarchist protests. In covering one protest outside Pillsbury headquarters, journalists exhibited the practice of omission by failing to note the protesters' central critique that Pillsbury's Burger King brand was contributing to the destruction of the rain forest by buying Brazilian beef. News stories engaged in distraction by emphasizing the protesters' conflict with the police, rather than their intended adversary, Pillsbury. The reports also exemplified trivialization by emphasizing various aspects of protester deviance to downgrade the legitimacy of considerations raised by the protesters. Such practices may reduce the potential influence of a particular consideration when audience members engage in subsequent judgments and experiences relevant to issues being raised. From the perspective of media use, audiences actively use certain news outlets that provide particular attributes of unfolding issues or events (Weaver, Wojdynski, McKeever, \& Shaw, 2010). This media use pattern may result in creating the association between a certain attribute (e.g., unimportant) with an issue in people's minds (Vargo, Guo, McCombs, \& Shaw, 2014). As a result, an issue that the media portray as unimportant is likely to be imbued with the attribute, and thus be disregarded when people make political judgments (Geer, 1991; Martin, 1986).

The reverse agenda setting and reverse priming potential of messages can also be substantiated within the framework of the predominant cognitive processing model. The socialpsychological literature (e.g., Higgins, 1996; Higgins \& Bargh, 1987) has long observed that priming effects are a product of two parts, one is to activate a certain consideration by a stimulus material (i.e., priming) and the other is to evaluate the goodness of fit between activated considerations and a subsequent judgment (i.e., judged usability). For example, a choice of what to prime (e.g., Higgins \& Brendl, 1995; Higgins, Rholes, \& Jones, 1977) and what criteria to evoke in evaluating primed considerations (e.g., Devine, 1989; Kruglanski, 1989) can independently make a difference in priming effects.

First, reverse agenda setting and reverse priming can occur through controlling knowledge activation. As knowledge activation is a function of accessibility and applicability (Higgins, 1989), lowering accessibility, applicability, or a combination of both can inhibit activation of certain considerations, thereby reducing the likelihood of those thoughts being used for cognitive tasks. Lowering accessibility can only be attained by ignoring target thoughts (i.e., omission) or by promoting rival thoughts and ignoring target thoughts simultaneously for stronger effects (i.e., distraction) (Higgins \& Brendl, 1995; Zhu, 1992) because a simple mentioning of a consideration is sufficient to increase the accessibility of that consideration (Carpentier, 2014; Miller, 2007).

Anecdotally, Bill Clinton's famous campaign slogan, "It's the economy, stupid," embodied a campaign strategy that successfully muted other issues by exclusively promoting the ailing economy as the top priority. Empirically, lack of news coverage is found to impact the standards by which citizens evaluate political actors (e.g., Iyengar et al., 1982) and the perceptions of issue importance (e.g., Iyengar \& Simon, 1993). Iyengar and colleagues' (Iyengar et al., 1984) study is particularly illustrative to this point. In their experiment, participants were assigned to one of three television news viewing conditions--high, intermediate and no coverage of three different issues including energy, defense, and inflation. After watching the news, respondents were asked to judge the importance of various national problems and presidential performance. Results showed that there was a positive relationship between the amount of exposure and the likelihood of those issues influencing presidential performance evaluations and being cited as the MIP. In other words, though all of the issues studied have potential to be seen as impactful, it is the existence of media coverage that determines the actual use of the issues in people's judgments. Likewise, the surge of the Iran-Contra scandal coverage effectively immediately muted the impact of welfare policies on presidential evaluations (Krosnick \& Kinder, 1990).

Similarly, prior activation of competing considerations can inhibit subsequent activation of target considerations. Considerations exhibit "hydraulic effects" in which the elevation of one consideration is associated with the simultaneous lowering of other considerations (N.-J. Lee, McLeod, \& Shah, 2008; Pan \& Kosicki, 1997). Higgins (1996) pointed out that rival constructs tend to compete with each other for activation such that a construct activated first inhibits its rival from rising above the threshold of consciousness. A1though not designed to test this hypothesis, Geer (1991) 
provided indirect evidence for this point. In his experiment, after reading one of the three articles about President Bush's handling of issues considered by participants to be important, unimportant or irrelevant, participants stated reasons for voting or not voting for the president in the upcoming election. A content analysis of their responses revealed that, although news articles failed to promote issues unimportant or irrelevant to voting decisions as voting criteria, they substantially weakened the role of important issues in voting decisions. These findings suggest that even though attempts to prime certain thoughts (i.e., unimportant and irrelevant issues) fail, such attempts may inhibit the use of rival thoughts (i.e., important issues) (see also Newman \& Uleman, 1990).

In addition to altering accessibility of issues, the nature of a media message, especially how it frames certain issues, can influence applicability of alternative perspectives of an issue (Price \& Tewksbury, 1997). Perspectives not applicable to message frames are less likely to be activated, and thus having low likelihood of affecting one's judgments. Substantial evidence indicates that message frames can induce corresponding thoughts, while suppressing rival considerations (Iyengar \& Kinder, 1987; Nelson, Clawson, et al., 1997; Price et al., 1997; F. Shen, 2004; L. Shen, 2010). To illustrate this point, F. Shen (2004) found that political ads highlighting issue positions evoked more issue-related thoughts than thoughts pertaining to character, while character-framed political ads had the opposite effect. More importantly, these findings held true regardless of chronic accessibility, suggesting that applicability overrides accessibility in such a way that frame-corresponding thoughts become activated at the expense of rival considerations regardless of whether the rival thoughts are always highly accessible from memory. In a similar vein, Higgins and Brendl's (1995) "Activation rule 3 " illustrates that even though a certain consideration is accessible, framing an issue in a way that renders a rival consideration applicable activates the latter instead of the former. Consequently, the previously accessible thought is not likely to play a role in priming processes because it fails to be activated. In sum, framing can selectively activate applicable thoughts, while inhibiting the activation of non-applicable alternatives.

Although activated knowledge has a heightened likelihood of being used for cognitive tasks, its actual use "depends on the knowledge meeting some accuracy criteria rather than its speed or ease of activation or its simple pri- macy" (Higgins, 1996, p. 162). Because activated knowledge deemed inappropriate, irrelevant, or both is screened out before its actual use, not all activated knowledge plays a role. In this sense, controlling knowledge use can be seen as the second barrier to the use of activated constructs.

Media messages can actively attack a consideration to render it unworthy of attention (i.e., trivialization) or less relevant to the issue in question (i.e., sidelining) as a way of reducing its usability for a given judgment. To date, most of the messages that were examined in previous priming and agenda-setting research have been framed to highlight the consequences and implications of the issue in question in accordance with traditional journalistic news values, thereby rendering activated issue-related thoughts usable for political evaluations.

This may not be always the case, however, especially in the partisan environment of contemporary media and politics. The partisan leaning of news organizations, as well as partisan columnists and bloggers, may foster more active attempts to challenge or trivialize a particular consideration. An example can be found in explicit differences of opinion on the relative threat posed by the size of the U.S. federal deficit. Gerald Seib, a right-leaning columnist for The Wall Street Journal, argued that Standard and Poor's downgrading of the U.S. government's debt rating signals the "stark reality" of grave consequences of the federal debt (Seib, 2011). By contrast, Floyd Norris, a columnist at The New York Times, dismissed concerns about the federal deficit, claiming that the national debt would soon become "livable" even "without Congress doing anything" (Norris, 2011). Among those who read The New York Times column, the usability of U.S. credit rating would decrease for MIP judgments and presidential performance evaluations because it is described as the kind of issue that occurs and should be resolved spontaneously, having nothing to do with the Obama administration's handling of the economy.

Another example is Paul Krugman's (2015) column about the Keystone XL oil pipeline extension plan. Krugman claimed that the job creation effects of the project, as its proponents argued, was not an important consideration. Krugman begins by admitting that "[b]uilding Keystone XL could slightly increase U.S. employment. In fact, it might replace almost 5 percent of the jobs America has lost because of destructive cuts in federal spending." The Nobel laureate then portrayed the job creation consideration as insignificant by arguing that: 
And the job gains from the pipeline would, as I said, be only a tiny fraction - less than 5 percent - of the job losses from sequestration, which in turn are only part of the damage done by spending cuts in general. (para. 11)

The numbers being thrown around are tiny compared with the country's overall work force. And in any case, the jobs argument for the pipeline is basically a sick joke coming from people who have done all they can to destroy American jobs - and are now employing the very arguments they used to ridicule government job programs to justify a big giveaway to their friends in the fossil fuel industry. (para. 12)

His column, if understood as intended, may call into question the importance and relevance of the job creation effects of the project, thereby rendering it less influential, or even screened out, when individuals try to make up their minds about the project. Similarly, issues that are described as resolved or no longer significant are less likely to be cited as the MIP (Miller, 2007).

As such, information sources, especially partisan media, may tell people not only "what to think about" (Cohen, 1963, p.16), but also "what not to think about" by marginalizing or downplaying certain issues so that trivialized issues should be screened out in making political judgments. Since judged usability can be decreased by directly dealing with target issues, reverse agenda setting and reverse priming of this sort can be seen as direct in nature. Also, attacking the usability of issues can be accompanied by promoting competing issues. Because people tend to fill a temporary cognitive vacuum created by the suppression of a certain idea with alternatives (N.-J. Lee et al., 2008; Price et al., 1997; Zhu, 1992), presenting viable alternatives while discounting target considerations is likely to expedite or intensify reverse agenda setting and reverse priming effects.

\section{Other Reverse Agenda Setting and Reverse Priming Mechanisms.}

In addition to the processes discussed above, reverse agenda setting and reverse priming effects may be triggered by various journalistic practices such as juxtaposition, visual enhancement, and slanted headlines. Juxtaposition refers to presenting competing issues or perspectives within a text in a way that spatially accentuates one over the other. Since perceived importance can be dependent upon the amount of processing time and attention (Scheufele \& Tewksbury, 2007), allocating more attention and space is likely to lead viewers to infer relative importance of particular considerations even though they are not explicitly promoted. Thus, issues or perspectives given less space and attention in a news article become relatively marginalized. In addition, considerations that are placed more prominently in a news story (e.g., in the lead or high up in a newspaper story as opposed to further down in the story) are more likely to be seen as more important. Moreover, similar to issue framing, other content elements such as photographs (Zillmann, Gibson, \& Sargent, 1999) and slanted headlines (Geer \& Kahn, 1993) that highlight particular interpretations over others may prevent neglected aspects from being activated.

\section{Conclusion}

This theoretical analysis of the cognitive effects literature sheds important light on mass communication effects such as agenda setting, framing, and media priming. Despite the long history and the immense volume of research on the cognitive effects of mass communication, there remains considerable confusion over the processes through which such effects occur as well as over their relationships to each other. For example, some argue that framing is a secondary effect of agenda setting, and media priming is an extension of agenda setting, whereas others have maintained that both media priming and agenda setting are a product of framing effects. Amid this confusion, we raised a fundamental question as to whether these types of effects that share the same stimulus messages and examine perceptions of a similar sort have different underlying processes. If those effects occur via the same psychological routes, it would be safe to conclude that agenda setting, framing, and media priming are just different names for the same media effects that imbue an object (e.g., issues and considerations) with certain attributes, but are examined with different dependent variables according to different judgment contexts.

A comprehensive examination of current evidence indicates that agenda setting, framing, and media priming effects in fact share the same cognitive processes. Although news stories as a stimulus bring to mind thoughts related to the attended features of the message, it is particular properties such as importance judgment and negative emotions imbued by the message content that mediate those media effects 
(Miller, 2007; Miller \& Krosnick, 2000; Nelson, Oxley, et al., 1997). In other words, rather than seeing accessibility solely responsible for some of the effects and applicability for others, it can be concluded that the enhanced fit between issues discussed in the message and a given judgment (i.e., judged usability) produces agenda setting, framing, and media priming effects. Indeed, given that news stories inevitably describe events and issues in a way that gives certain considerations related to the story more emphasis than others, meanings gleaned by the audience are likely to be similarly skewed. This basic principle of elevated considerations is common to each of the cognitive effects identified above.

Based on the conclusion we made above that cognitive media effects models including agenda setting, framing, and media priming occur through the same processes, we believe that the attitude formation formula (i.e., Attitude $=\sum v_{i}{ }^{*} w_{i}$ ), which typically is used to explain framing effects, can be generalized to agenda setting and media priming. In turn, we incorporate the concept of judged usability, which evidence indicates plays a mediating role, into the formula so it can more precisely identify the elements determining the fate of considerations and illustrate the processes underlying those effects. Thus, the Judged Usability Model is an extrapolation of reconceptualizing agenda setting, framing, and media priming as media effects that share the same psychological mechanisms.

The Judged Usability Model (i.e., Judgment $=\sum I_{i}{ }^{*} R_{i}{ }^{*}$ $\left.E_{i}\right)$ applies perceived importance (i.e., $I_{i}$ ) and relevance (i.e., $R_{i}$ ) in place of the rather vague concept of weight in the formula (i.e., $w_{i}$ ) for each consideration used to evaluate a target (e.g., a president's job performance) and then aggregated into a summary judgment. While importance is congruent with the previous conceptualization of weight (N. H. Anderson, 1981; Van der Pligt \& Eiser, 1984), our updated formula includes the impact that a message can have not only on raising or lowering the salience of various considerations, but also on affecting their judged usability for subsequent judgments. Our model is fairly simple to apply to a range of judgment contexts in which individuals weigh various considerations.

Also noteworthy is that the way each component of The Judged Usability Model is specified illuminates a dormant aspect of media priming research-by altering the values of the elements, media messages can not only promote a certain consideration for a judgment (i.e., media priming), but also can displace one in the judgment-making process (i.e., reverse agenda setting and reverse priming). Though not fully explored to date, neither theoretically nor empirically, examples of potential reverse agenda setting and reverse priming can be seen in all types of news coverage. Political strategists routinely attempt to bury issues that play to their candidate's weakness and opponent's strengths, which may be just as important as raising issues that favor the strength of their candidate (West, 2005). When media messages, whether intentionally or unintentionally, reduce the viability of certain considerations in the pool of political evaluation standards, there are considerable political implications. Thus, researchers can provide a more comprehensive picture of the interaction between mediated messages and subsequent political judgments by taking reverse agenda setting and reverse priming into account.

In summary, there are three main contributions of this theoretical review: a) redefining and further specifying the relationships among agenda setting, framing, and media priming; $b$ ) proposing a refined model of cognitive media effects, the Judged Usability Model; and c) identifying the reverse agenda setting and reverse priming hypotheses, a logical extension of our new model that describes a phenomenon that can often be observed in social and political life. In the process, we hope to resolve theoretical conflicts over the nature of cognitive media effects and offer a meaningful framework for further systematic investigations. 


\section{References}

Althaus, S. L., \& Kim, Y. M. (2006). Priming effects in complex information environments: Reassessing the impact of news discourse on presidential approval. The Journal of Politics, 68(4), 960-976. https://doi.org/10.1111/j.1468-2508.2006.00483.x

Althaus, S. L., \& Tewksbury, D. (2002). Agenda setting and the "new" news: Patterns of issue importance among readers of the paper and online versions of the New York Times. Communication Research, 29(2), 180-207.

Anderson, J. R. (1983). The architecture of cognition. Cambridge, MA: Harvard University Press.

Anderson, N. H. (1981). Foundations of information integration theory. New York: Academic Press.

Benton, M., \& Frazier, J. P. (1976). The agenda setting function of the mass media at three levels of "information holding". Communication Research, 3(3), 261-274.

Brewer, P. R., Graf, J., \& Willnat, L. (2003). Priming or framing: Media influence on attitudes toward foreign countries. International Communication Gazette, 65(6), 493-508.

Carpentier, F. D. (2014). Agenda setting and priming effects based on information presentation: Revisiting accessibility as a mechanism explaining agenda setting and priming. Mass Communication \& Society, 17(4), 531-552. https://doi.org/ $10.1080 / 15205436.2013 .816744$

Chaiken, S. (1980). Heuristic versus systematic information processing and the use of source versus message cues in persuasion. Journal of Personality and Social Psychology, 39(5), 752-766. https://doi.org/10.1037/0022-3514.39.5.752

Chaiken, S. (1987). The heuristic model of persuasion. In M. P. Zanna, J. M. Olson, \& C. P. Herman (Eds.), Social influence: The Ontario Symposium (Vol. 5, pp. 3-39). Hillsdale, NJ: Erlbaum.

Chaiken, S., Wood, W., \& Eagly, A. H. (1996). Principles of persuasion. In E. Tory Higgins \& Arie W. Kruglansk (Eds.), Social psychology: Handbook of basic principles. New York: Guilford Press.

Chong, D. (1993). How people think, reason, and feel about rights and liberties. American Journal of Political Science, 37, 867-899.

Chong, D., \& Druckman, J. N. (2007a). A theory of framing and opinion formation in competitive elite environments. Journal of Communication, 57(1), 99-118. https://doi.org/10.1111/j.1460-2466.2006.00331_2.x

Chong, D., \& Druckman, J. N. (2007b). Framing theory. Annual Review of Political Science, 10(1), 103-126. https://doi. org/10.1146/annurev.polisci.10.072805.103054

Cohen, B. C. (1963). The press and foreign policy. Princeton, NJ: Princeton University Press.

Collins, A. M., \& Loftus, E. F. (1975). A spreading-activation theory of semantic processing. Psychological Review, 82(6), 407-428. https://doi.org/10.1037/0033-295X.82.6.407

Conway, B. A., Kenski, K., \& Wang, D. (2015). The rise of Twitter in the political campaign: Searching for intermedia agenda-setting effects in the presidential primary. Journal of Computer-Mediated Communication, 20(4), 363-380. https:// doi.org/10.1111/jcc4.12124

Cook, F. L., Tyler, T. R., Goetz, E. G., Gordon, M. T., Protess, D., Leff, D. R., \& Molotch, H. L. (1983). Media and agenda setting: Effects on the public, interest group leaders, policy makers, and policy. Public Opinion Quarterly, 47, 16-35.

Corbett, J. B., \& Durfee, J. L. (2004). Testing public (un)certainty of science media representations of global warming. Science Communication, 26(2), 129-151. https://doi.org/10.1177/1075547004270234

Croizet, J.-C., \& Fiske, S. T. (2000). Moderation of priming by goals: Feeling entitled to judge increases judged usability of evaluative primes. Journal of Experimental Social Psychology, 36(2), 155-181. https://doi.org/10.1006/jesp.1999.1397

Danes, J. E., Hunter, J. E., \& Woelfel, J. (1978). Mass communication and belief change: A test of three mathematical models. Human Communication Research, 4(3), 243-252. https://doi.org/10.1111/j.1468-2958.1978.tb00613.x

Dearing, J. W. (1995). Newspaper coverage of maverick science: Creating controversy through balancing. Public Understanding of Science, 4(4), 341-361. https://doi.org/10.1088/0963-6625/4/4/002

Dearing, J. W., \& Rogers, E. M. (1996). Agenda setting. Thousand Oaks, CA: Sage Publications.

Devine, P. G. (1989). Stereotypes and prejudice: Their automatic and controlled components. Journal of Personality and Social Psychology, 56(1), 5-18. https://doi.org/10.1037/0022-3514.56.1.5 
Dodel, M., Comesaña, F., \& Blanc, D. (2019). A case of reverse-agenda setting? How 2018's FIFA World Cup coverage reduced media reporting of Uruguayan budget bill's yearly revision. International Symposium on Online Journalism, 9(1), $13-28$.

Domke, D., Shah, D. V., \& Wackman, D. B. (1998). Media priming effects: Accessibility, association, and activation. International Journal of Public Opinion Research, 10(1), 51-74. https://doi.org/10.1093/ijpor/10.1.51

Druckman, J. N. (2001a). On the limits of framing effects: Who can frame? The Journal of Politics, 63(4), $1041-1066$.

Druckman, J. N. (2001b). The implications of framing effects for citizen competence. Political Behavior, 23(3), $225-256$.

Druckman, J. N. (2004). Priming the vote: Campaign effects in a US Senate election. Political Psychology, 25(4), 577-594.

Eagly, A. H., \& Chaiken, S. (1993). The psychology of attitudes. Belmont, CA: Wadsworth Cengage Learning.

Entman, R. M. (1991). Framing United-States coverage of international news-Contrasts in narratives of the KAL and Iran Air incidents. Journal of Communication, 41(4), 6-27.

Entman, R. M. (1993). Framing: Toward clarification of a fractured paradigm. Journal of Communication, 43(4), 51-58. https:// doi.org/10.1111/j.1460-2466.1993.tb01304.x

Entman, R. M. (2007). Framing bias: Media in the distribution of power. Journal of Communication, 57(1), 163-173. https:// doi.org/10.1111/j.1460-2466.2006.00336.x

Entman, R. M. (2010). Media framing biases and political power: Explaining slant in news of Campaign 2008. Journalism, 11(4), 389-408. https://doi.org/10.1177/1464884910367587

Fazio, R. H., Blascovich, J., \& Driscoll, D. M. (1992). On the functional value of attitudes: The influence of accessible attitudes on the ease and quality of decision making. Personality and Social Psychology Bulletin, 18(4), 388-401. https://doi. org/10.1177/0146167292184002

Fischhoff, B., Slovic, P., \& Lichtenstein, S. (1977). Knowing with certainty: The appropriateness of extreme confidence. Journal of Experimental Psychology: Human Perception and Performance, 3(4), 552-564. https://doi.org/10.1037/0096-1523.3.4.552

Fishbein, M. (1963). An investigation of the relationship between beliefs about an object and the attitude toward that object. Human Relations, 16(3), 233-239. https://doi.org/10.1177/001872676301600302

Gamson, W. A., \& Modigliani, A. (1989). Media discourse and public opinion on nuclear power: A constructionist approach. American Journal of Sociology, 95(1), 1-37. https://doi.org/10.1086/229213

Geer, J. G. (1991). Do open-ended questions measure "salient" issues? Public Opinion Quarterly, 55(3), 360-370. https://doi. org/10.1086/269268

Geer, J. G., \& Kahn, K. F. (1993). Grabbing attention: An experimental investigation of headlines during campaigns. Political Communication, 10(2), 175-191.

Gelbspan, R. (1998). The heat is on: The climate crisis, the cover-up, the prescription. New York: Perseus.

Gitlin, T. (1980). The whole world is watching: Mass media in the making \& unmaking of the new left. Berkeley, CA: University of California Press.

Goffman, E. (1974). Frame analysis: An essay on the organization of experience. Boston: Northeastern University Press.

Hänze, M. (2001). Ambivalence, conflict, and decision making: Attitudes and feelings in Germany towards NATO's military intervention in the Kosovo war. European Journal of Social Psychology, 31(6), 693-706. https://doi.org/10.1002/ejsp.57

Hart, A., \& Middleton, J. A. (2014). Priming under fire: Reverse causality and the classic media priming hypothesis. The Journal of Politics, 76(2), 581-592. https://doi.org/10.1017/s0022381613001539

Hastie, R., \& Park, B. (1986). The relationship between memory and judgment depends on whether the judgment task is memory-based or on-line. Psychological Review, 93(3), 258-268. https://doi.org/10.1037/0033-295x.93.3.258

Higgins, E. T. (1989). Knowledge accessibility and activation: Subjectivity and suffering from unconscious sources. In J. S. Uleman \& J. A. Bargh (Eds.), Unintended thought: The limits of awareness, intention and control (pp. 75-123). New York: Guilford.

Higgins, E. T. (1996). Knowledge activation: Accessibility, applicability, and salience. In E. T. Higgins \& A. W. Kruglanski (Eds.), Social psychology: Handbook of basic principles (pp. 133-168). New York: Guilford. 
Higgins, E. T., \& Bargh, J. A. (1987). Social cognition and social perception. Annual Review of Psychology, 38(1), 369-425. https://doi.org/10.1146/annurev.ps.38.020187.002101

Higgins, E. T., \& Brendl, C. M. (1995). Accessibility and applicability: Some "activation rules" influencing judgment. Journal of Experimental Social Psychology, 31(3), 218-243. https://doi.org/10.1006/jesp.1995.1011

Higgins, E. T., Rholes, W. S., \& Jones, C. R. (1977). Category accessibility and impression formation. Journal of Experimental Social Psychology, 13(2), 141-154. https://doi.org/10.1016/S0022-1031(77)80007-3

Holbrook, A. R., \& Hill, T. G. (2005). Agenda-setting and priming in prime time television: Crime dramas as political cues. Political Communication, 22(3), 277-295. https://doi.org/10.1080/10584600591006519

Iyengar, S. (1991). Is anyone responsible?: How television frames political issues. Chicago, IL: University of Chicago Press.

Iyengar, S., \& Kinder, D. R. (1987). News that matters. Chicago, IL: University of Chicago Press.

Iyengar, S., Kinder, D. R., Peters, M. D., \& Krosnick, J. A. (1984). The evening news and presidential evaluations. Journal of Personality and Social Psychology, 46(4), 778-787. https://doi.org/10.1037/0022-3514.46.4.778

Iyengar, S., Peters, M. D., \& Kinder, D. R. (1982). Experimental demonstrations of the "not-so-minimal" consequences of television news programs. The American Political Science Review, 848-858.

Iyengar, S., \& Simon, A. (1993). News coverage of the Gulf crisis and public opinion. Communication Research, 20(3), 365-383. https://doi.org/10.1177/009365093020003002

Johnston, R., Andre Blais, Henry E. Brady, \& Jean Crete. (1992). Letting the people decide: Dynamics of a Canadian election. Stanford, CA: Stanford University Press.

Jonas, K., Diehl, M., \& Brömer, P. (1997). Effects of attitudinal ambivalence on information processing and attitude-intention consistency. Journal of Experimental Social Psychology, 33(2), 190-210. https://doi.org/10.1006/jesp.1996.1317

Kahneman, D., \& Tversky, A. (1979). Prospect theory: An analysis of decision under risk. Econometrica: Journal of the Econometric Society, 47(2), 263-291.

Kahneman, D., \& Tversky, A. (1984). Choices, values, and frames. American Psychologist, 39, 341-350.

Kim, S.-H., Scheufele, D. A., \& Shanahan, J. (2002). Think about it this way: Attribute agenda-setting function of the press and the public's evaluation of a local issue. Journalism and Mass Communication Quarterly, 79(1), 7-25. https://doi. org/10.1177/107769900207900102

Kim, Y. M. (2005). Use and disuse of contextual primes in dynamic news environments. Journal of Communication, 55(4), 737-755. https://doi.org/10.1111/j.1460-2466.2005.tb03020.x

Kinder, D. R., \& Sanders, L. M. (1996). Divided by color: Racial politics and democratic ideals. Chicago: University of Chicago Press.

Kosicki, G. M. (1993). Problems and opportunities in agenda-setting research. Journal of Communication, 43(2), 100-127. https://doi.org/10.1111/j.1460-2466.1993.tb01265.x

Krosnick, J. A., \& Kinder, D. R. (1990). Altering the foundations of support for the president through priming. The American Political Science Review, 84(2), 497-512. https://doi.org/10.2307/1963531

Kruglanski, A. W. (1989). Lay epistemics and human knowledge: Cognitive and motivational bases. New York: Springer Science+Business Media.

Kruglanski, A. W., Dechesne, M., Orehek, E., \& Pierro, A. (2009). Three decades of lay epistemics: The why, how, and who of knowledge formation. European Review of Social Psychology, 20(1), 146-191. https://doi.org/10.1080/10463280902860037

Krugman, P. (2015, January 11). For the love of carbon. The New York Times.

Lee, B., Liu, J., Choung, H., \& McLeod, D. M. (2019). Framing risk with numbers: The framing effects of risk assertions and number formats on emotions and risk perceptions. Mass Communication \& Society, 22(3), 344-364. https://doi.org/ $10.1080 / 15205436.2018 .1536790$

Lee, N. Y. (2016). Two different motivations on agenda setting: Need for orientation and motivated reasoning. International Journal of Public Opinion Research, 28(4), 484-510. https://doi.org/10.1093/ijpor/edv029

Lee, N.-J., McLeod, D. M., \& Shah, D. V. (2008). Framing policy debates: Issue dualism, journalistic frames, and opinions on controversial policy issues. Communication Research, 35(5), 695-718. 
Lenz, G. S. (2009). Learning and opinion change, not priming: Reconsidering the priming hypothesis. American Journal of Political Science, 53(4), 821-837. https://doi.org/10.1111/j.1540-5907.2009.00403.x

Liu, J., Choung, H., Lee, B., \& McLeod, D. (2018). Framing obesity: Effects of obesity labeling and prevalence statistics on public perceptions. Health Education \& Behavior, 46(2), 322-328. https://doi.org/10.1177/1090198118788907

Liu, J., \& Scheufele, D. A. (2016). A revisionist perspective on framing effects. In W. R. Thompson (Ed.), Oxford research encyclopedia of politics. New York: Oxford University Press.

Luce, M. F., Bettman, J. R., \& Payne, J. W. (1997). Choice processing in emotionally difficult decisions. Journal of Experimental Psychology: Learning, Memory, and Cognition, 23(2), 384-405. https://doi.org/10.1037/0278-7393.23.2.384

Luttig, M. D., \& Callaghan, T. H. (2016). Is President Obama's race chronically accessible? Racial priming in the 2012 Presidential Election. Political Communication, 33(4), 628-650. https://doi.org/10.1080/10584609.2016.1166168

Maher, T. M. (2001). Framing: An emerging paradigm or a phase of agenda setting? In O. H. G. S. D. Reese (Ed.), Framing public life: Perspectives on media and our understanding of the social world (pp. 83-94). Mahwah, NJ: Erlbaum.

Martin, L. L. (1986). Set/reset: Use and disuse of concepts in impression formation. Journal of Personality and Social Psychology, 51(3), 493-504. https://doi.org/10.1037/0022-3514.51.3.493

Matthes, J. (2006). The need for orientation towards news media: Revising and validating a classic concept. International Journal of Public Opinion Research, 18(4), 422-444. https://doi.org/10.1093/ijpor/edh118

Matthes, J. (2008). Need for orientation as a predictor of agenda-setting effects: Causal evidence from a two-wave panel study. International Journal of Public Opinion Research, 20(4), 440-453. https://doi.org/10.1093/ijpor/edn042

McCombs, M. E. (2004). Setting the agenda: The mass media and public opinion. Malden, MA: Polity.

McCombs, M. E., \& Estrada, G. (1997). The news media and the pictures in our heads. In S. Iyengar \& R. Reeves (Eds.), Do the media govern? Politicians, voters and reporters in America (pp. 237-247). London: Sage.

McCombs, M. E., \& Ghanem, S. I. (2001). The convergence of agenda setting and framing. In Stephen D. Reese, J. Oscar H. Gandy, \& August E. Grant (Eds.), Framing public life: Perspectives on media and our understanding of the social world (pp. 67-81). Mahwah, New Jersey: Lawrence Erlbaum.

McCombs, M. E., \& Shaw, D. L. (1972). The agenda-setting function of mass media. Public Opinion Quarterly, 36(2), 176-187. https://doi.org/10.1086/267990

McCombs, M. E., \& Shaw, D. L. (1977). The agenda-setting function of the press. In D. L. Shaw \& M. E. McCombs (Eds.), The emergence of American political issues: The agenda-setting function of the press (pp. 1-18). St. Paul, MN: West.

McCombs, M. E., \& Shaw, D. L. (1993). The evolution of agenda-setting research: Twenty-five years in the marketplace of ideas. Journal of Communication, 43(2), 58-67.

McCombs, M. E., Shaw, D. L., \& Weaver, D. H. (1997). Communication and democracy: Exploring the intellectual frontiers in agenda-setting theory. Mahwah, NJ: Erlbaum.

McCombs, M. E., \& Weaver, D. H. (1973, April 25). Voters' need for orientation and use of mass communication. Presented at the the International Communication Association, Montreal, Canada.

McLeod, D. M., \& Hertog, J. K. (1999). Social control, social change and the mass media's role in the regulation of protest groups: The communicative acts perspective. In D. Demers \& K. Viswanath (Eds.), Mass media, social control, and social change (pp. 305-330). Ames, IA: Iowa State University Press.

McLeod, D. M., \& Shah, D. V. (2011). Framing the war on terror: The struggle over civil liberties in the age of terrorism. Cambridge: Cambridge University Press.

McLeod, D. M., \& Shah, D. V. (2015). News frames and national security: Covering big brother. Cambridge, UK: Cambridge University Press.

Mendelberg, T. (2001). The race card: Campaign strategy, implicit messages, and the norm of equality. Princeton, NJ: Princeton University Press.

Meraz, S. (2009). Is there an elite hold? Traditional media to social media agenda setting influence in blog networks. Journal of Computer-Mediated Communication, 14(3), 682-707. https://doi.org/10.1111/j.1083-6101.2009.01458.x 
Miller, J. M. (2007). Examining the mediators of agenda setting: A new experimental paradigm reveals the role of emotions. Political Psychology, 28(6), 689-717. https://doi.org/10.1111/j.1467-9221.2007.00600.x

Miller, J. M., \& Krosnick, J. A. (1996). News media impact on the ingredients of presidential evaluations: A program of research on the priming hypothesis. In Diana C. Mutz, Paul M. Sniderman, \& Richard A. Brody (Eds.), Political persuasion and attitude change (pp. 79-100). Ann Arbor, MI: The University of Michigan Press.

Miller, J. M., \& Krosnick, J. A. (2000). News media impact on the ingredients of presidential evaluations: Politically knowledgeable citizens are guided by a trusted source. American Journal of Political Science, 44(2), 301-315. https://doi. org/10.2307/2669312

Min, Y., Ghanem, S. I., \& Evatt, D. (2007). Using a split-ballot survey to explore the robustness of the 'MIP' question in agenda-setting research: A methodological study. International Journal of Public Opinion Research, 19(2), 221-236. https:// doi.org/10.1093/ijpor/edm003

Mutz, D. C. (1998). Impersonal influence: How perceptions of mass collectives affect political attitudes. New York: Cambridge University Press.

Nabi, R. L., Gustafson, A., \& Jensen, R. (2018). Framing climate change: Exploring the role of emotion in generating advocacy behavior. Science Communication, 40(4), 442-468. https://doi.org/10.1177/1075547018776019

Nelson, T. E., Clawson, R. A., \& Oxley, Z. M. (1997). Media framing of a civil liberties conflict and its effect on tolerance. American Political Science Review, 91(3), 567-583. https://doi.org/10.2307/2952075

Nelson, T. E., \& Kinder, D. R. (1996). Issue frames and group-centrism in American public opinion. The Journal of Politics, 58(4), 1055-1078.

Nelson, T. E., \& Oxley, Z. M. (1999). Issue framing effects on belief importance and opinion. The Journal of Politics, 61(4), 1040-1067. https://doi.org/10.2307/2647553

Nelson, T. E., Oxley, Z. M., \& Clawson, R. A. (1997). Toward a psychology of framing effects. Political Behavior, 19(3), 221-246. https://doi.org/10.1023/A:1024834831093

Newman, L. S., \& Uleman, J. S. (1990). Assimilation and contrast effects in spontaneous trait inference. Personality and Social Psychology Bulletin, 16(2), 224-240.

Norris, F. (2011, April 22). Reassuring deficit news. The New York Times.

Page, B. I., \& Shapir, R. Y. (1992). The rational public. Chicago: University of Chicago Press.

Pan, Z., \& Kosicki, G. M. (1997). Priming and media impact on the evaluations of the president's performance. Communication Research, 24(1), 3-30. https://doi.org/10.1177/009365097024001001

Pedersen, R. T. (2017). Ratio bias and policy preferences: How equivalency framing of numbers can affect attitudes. Political Psychology, 38(6), 1103-1120. https://doi.org/10.1111/pops.12362

Pedersen, R. T., \& Larsen, M. V. (2019). Putting a number on preferences: How numerical attitudes are shaped by ideology and equivalency framing. International Journal of Public Opinion Research, 31(3), 528-548. https://doi.org/10.1093/ijpor/ edy020

Petty, R. E., \& Cacioppo, J. T. (1979). Issue involvement can increase or decrease persuasion by enhancing message-relevant cognitive responses. Journal of Personality and Social Psychology, 37(10), 1915-1926. https://doi.org/10.1037/0022-3514.37.10.1915

Petty, R. E., \& Cacioppo, J. T. (2012). Communication and persuasion: Central and peripheral routes to attitude change. New York: Springer Science+Business Media.

Pingree, R. J., \& Stoycheff, E. (2013). Differentiating cueing from reasoning in agenda-setting effects. Journal of Communication, 63(5), 852-872.

Price, V., \& Tewksbury, D. (1997). News values and public opinion: A theoretical account of media priming and framing. In G. Barnett \& F. Boster (Eds.), Progress in communication sciences (Vol. 13, pp. 173-212). Greenwich, CT: Ablex.

Price, V., Tewksbury, D., \& Powers, E. (1997). Switching trains of thought: The impact of news frames on readers' cognitive responses. Communication Research, 24(5), 481-506. https://doi.org/10.1177/009365097024005002

Quattrone, G. A., \& Tversky, A. (1988). Contrasting rational and psychological analyses of political choice. American Political Science Review, 82(3), 719-736. https://doi.org/10.2307/1962487 
Roessler, P., \& Eichhorn, W. (1999). Agenda setting. In Hans-Bernd Brosius \& Christina Holtz-Bacha (Eds.), The German communication yearbook (pp. 277-304). Cresskill, NJ: Hampton Press.

Rogers, E. M., Hart, W. B., \& Dearing, W. (1997). A paradigmatic history of agenda setting research. In S. Iyengar \& R. Reeves (Eds.), Do the media govern? Politicians, voters, and reporters in America (pp. 225-236). Thousand Oaks, CA: Sage.

Schattschneider, E. E. (1961). The semi-sovereign people. New York: Holt, Rinehart and Winston.

Scheufele, D. A. (1999). Framing as a theory of media effects. Journal of Communication, 49(1), 103-122.

Scheufele, D. A. (2000). Agenda-setting, priming, and framing revisited: Another look at cognitive effects of political communication. Mass Communication and Society, 3(2-3), 297-316. https://doi.org/10.1207/S15327825MCS0323_07

Scheufele, D. A., \& Tewksbury, D. (2007). Framing, agenda setting, and priming: The evolution of three media effects models. Journal of Communication, 57(1), 9-20. https://doi.org/10.1111/j.0021-9916.2007.00326.x

Schuman, H., \& Presser, S. (1980). Public opinion and public ignorance: The fine line between attitudes and nonattitudes. American Journal of Sociology, 85(5), 1214-1225. https://doi.org/10.1086/227131

Seib, G. F. (2011, April 19). Deficit fix is elusive amid clashing narratives. The Wall Street Journal.

Shah, D. V., McLeod, D. M., Gotlieb, M. R., \& Lee, N.-J. (2010). Framing and agenda setting. In R. L. Nabi \& M. B. Oliver (Eds.), The Sage handbook of media processes and effects (pp. 83-98). Thousand Oaks, CA: Sage.

Shah, D. V., Watts, M. D., Domke, D., \& Fan, D. P. (2002). News framing and cueing of issue regimes: Explaining Clinton's public approval in spite of scandal. Public Opinion Quarterly, 66(3), 339-370. https://doi.org/10.1086/341396

Shaw, D. L., \& McCombs, M. E. (1977). The emergence of American political issues: The agenda setting function of the press. St. Paul, MN: West Publishing Co.

Sheafer, T. (2007). How to evaluate it: The role of story-evaluative tone in agenda setting and priming. Journal of Communication, 57(1), 21-39. https://doi.org/10.1111/j.0021-9916.2007.00327.x

Shen, F. (2004). Chronic accessibility and individual cognitions: Examining the effects of message frames in political advertisements. Journal of Communication, 54(1), 123-137. https://doi.org/10.1111/j.1460-2466.2004.tb02617.x

Shen, L. (2010). The effect of message frame in anti-smoking public service announcements on cognitive response and attitude toward smoking. Health Communication, 25(1), 11-21.

Sherif, M., \& Hovland, C. I. (1961). Social judgment: Assimilation and contrast effects in communication and attitude change. New Haven, CT: Yale University Press.

Skinner, A. L., \& Cheadle, J. E. (2016). The "Obama Effect"? Priming contemporary racial milestones increases implicit racial bias among whites. Social Cognition, 34(6), 544-558. https://doi.org/10.1521/soco.2016.34.6.544

Slothuus, R. (2008). More than weighting cognitive importance: A dual-process model of issue framing effects. Political Psychology, 29(1), 1-28.

Stoycheff, E., \& Nisbet, E. C. (2017). Priming the costs of conflict? Russian public opinion about the 2014 Crimean conflict. International Journal of Public Opinion Research, 29(4), 657-675. https://doi.org/10.1093/ijpor/edw020

Swanson, D. L. (1988). Feeling the elephant: Some observations on agenda-setting research. In J. A. Anderson (Ed.), Communication yearbook 11 (pp. 603-619). Newbury Park, CA: Sage.

Takens, J., Kleinnijenhuis, J., Van Hoof, A., \& Van Atteveldt, W. (2015). Party leaders in the media and voting behavior: Priming rather than learning or projection. Political Communication, 32(2), 249-267.

Takeshita, T. (2006). Current critical problems in agenda-setting research. International Journal of Public Opinion Research, 18(3), 275-296. https://doi.org/10.1111/j.0021-9916.2007.00326.x

Tiedens, L. Z., \& Linton, S. (2001). Judgment under emotional certainty and uncertainty: The effects of specific emotions on information processing. Journal of Personality and Social Psychology, 81(6), 973-988. https://doi. org/10.1037/0022-3514.81.6.973

Tversky, A., \& Kahneman, D. (1973). Availability: A heuristic for judging frequency and probability. Cognitive Psychology, 5(2), 207-232.

Tversky, A., \& Kahneman, D. (1981). The framing of decisions and the psychology of choice. Science, 211(4481), 453-458. https://doi.org/10.1126/science.7455683 
Valentino, N. A. (1999). Crime news and the priming of racial attitudes during evaluations of the president. Public Opinion Quarterly, 63(3), 293-320.

Valentino, N. A., Hutchings, V. L., \& White, I. K. (2002). Cues that matter: How political ads prime racial attitudes during campaigns. American Political Science Review, 96(1), 75-90. https://doi.org/10.1017/S0003055402004240

Van der Pligt, J., \& Eiser, J. R. (1984). Dimensional salience, judgment, and attitudes. In Richard Eiser (Ed.), Attitudinal judgment (pp. 161-177). New York: Springer-Verlag.

Vargo, C. J., Guo, L., McCombs, M., \& Shaw, D. L. (2014). Network issue agendas on Twitter during the 2012 U.S. Presidential Election. Journal of Communication, 64(2), 296-316. https://doi.org/10.1111/jcom.12089

Waal, E., \& Schönbach, K. (2008). Presentation style and beyond: How print newspapers and online news expand awareness of public affairs issues. Mass Communication and Society, 11(2), 161-176.

Weaver, D. H. (1977). Political issues and voter need for orientation. In D. L. Shaw \& M. E. McCombs (Eds.), The emergence of American public issues (pp. 107-120). St. Paul, MN: West.

Weaver, D. H. (1980). Audience need for orientation and media effects. Communication Research, 7(3), 361-376.

Weaver, D. H. (1991). Issue salience and public opinion: Are there consequences of agenda-setting? International Journal of Public Opinion Research, 3(1), 53-68.

Weaver, D. H. (2007). Thoughts on agenda setting, framing, and priming. Journal of Communication, 57(1), 142-147. https:// doi.org/10.1111/j.1460-2466.2006.00333.x

Weaver, D. H., Graber, D. A., McCombs, M. E., \& Eyal, C. H. (1981). Media agenda-setting in a presidential election: Issues, images, and interest. New York: Praeger.

Weaver, D. H., Wojdynski, B., McKeever, R., \& Shaw, D. (2010, May). Vertical and or versus? Horizontal communities: Need for orientation, media use and agenda melding. Presented at the Proceedings of the Annual Convention of the World Association for Public Opinion Research, Chicago, IL.

Weiss, H.-J. (1992). Public issues and augmentation structures: An approach to the study of the contents of media agendasetting. In S. A. Deetz (Ed.), Communication yearbook 15 (pp. 374-396). Newbury Park, CA: Sage.

West, D. M. (2005). Air wars: Television advertising in election campaigns, 1952-2004 (4 $4^{\text {th }}$ ed.). Washington, D.C.: CQ Press.

Willnat, L. (1997). Agenda setting and priming: Conceptual links and differences. In M. McCombs, D. L. Shaw, \& D. Weaver (Eds.), Communication and democracy: Exploring the intellectual frontiers in agenda-setting theory (pp. 51-66). Mahwah, NJ: Erlbaum.

Young, M. L. (1992). Dictionary of polling: The languages of contemporary opinion research. Westport, CT: Greenwood.

Zahry, N. R., \& Besley, J. C. (2019). Genetic engineering, genetic modification, or agricultural biotechnology: Does the term matter? Journal of Risk Research, 22(1), 16-31. https://doi.org/10.1080/13669877.2017.1351470

Zaller, J. (1992). The nature and origins of mass opinion. New York, NY: Cambridge University Press.

Zhu, J.-H. (1992). Issue competition and attention distraction: A zero-sum theory of agenda-setting. Journalism Quarterly, $69(4), 825-836$.

Zillmann, D., Gibson, R., \& Sargent, S. L. (1999). Effects of photographs in news-magazine reports on issue perception. Media Psychology, 1(3), 207-228. 


\section{Copyrights and Repositories}

\section{(\$) (1)}

This work is licensed under the Creative Commons Attribution-NonCommercial-3.0 Unported License.

This license allows you to download this work titled "Reconceptualizing Cognitive Media Effects Theory and Research Under the Judged Usability Model" and share it with others as long as you credit the authors and the journal. You cannot use it commercially without the written permission of the authors and the journal (Review of Communication Research).

\section{Attribution}

You must attribute the work to the author and mention the journal with a full citation, whenever a fragment or the full text of this paper is being copied, distributed or made accessible publicly by any means.

\section{Commercial use}

The licensor permits others to copy, distribute, display, and perform the work for non-commercial purposes only, unless you get the written permission of the authors and the journal.

The above rules are crucial and bound to the general license agreement that you can read at:

http://creativecommons.org/licenses/by-nc/3.0/

\section{Corresponding author}

Douglas M. McLeod

School of Journalism \& Mass Communication at the University of Wisconsin-Madison

Email:dmmcleod@wisc.edu

\section{Attached is a list of permanent repositories where you can find the articles published by RCR:}

Academia.edu @ http://independent.academia.edu/ReviewofCommunicationResearch Internet Archive @ http://archive.org (collection "community texts")

Social Science Open Access Repository, SSOAR@ @ http://www.ssoar.info/en/home.html 